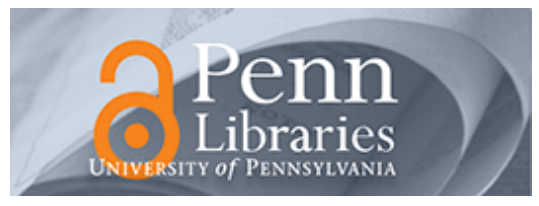

University of Pennsylvania

ScholarlyCommons

Finance Papers

Wharton Faculty Research

9-28-2016

\title{
Partial Adjustment to Public Information in the Pricing of IPOs
}

Einar Bakke

Tore E. Leite

Karin S. Thorburn

University of Pennsylvania

Follow this and additional works at: https://repository.upenn.edu/fnce_papers

Part of the Finance and Financial Management Commons

\section{Recommended Citation}

Bakke, E., Leite, T. E., \& Thorburn, K. S. (2016). Partial Adjustment to Public Information in the Pricing of IPOs. Journal of Financial Intermediation, http://dx.doi.org/10.1016/j.jfi.2016.09.003

This paper is posted at ScholarlyCommons. https://repository.upenn.edu/fnce_papers/53

For more information, please contact repository@pobox.upenn.edu. 


\title{
Partial Adjustment to Public Information in the Pricing of IPOs
}

\begin{abstract}
Extant literature shows that IPO first-day returns are correlated with market returns preceding the issue. We propose a rational explanation for this puzzling predictability by adding a public signal to Benveniste and Spindt (1989)'s information-based framework. A novel result of our model is that the compensation required by investors to truthfully reveal their information decreases with the public signal. This "incentive effect" receives strong empirical support in a sample of 6300 IPOs in 1983-2012. Controlling for the incentive effect, the positive relation between initial returns and pre-issue market returns disappears for top-tier underwriters, where the order book is held to be most informative, effectively resolving the predictability puzzle.
\end{abstract}

\section{Keywords}

IPO, underpricing, bookbuilding, public information, private information, partial adjustment

\section{Disciplines}

Business | Finance and Financial Management 


\title{
Partial Adjustment to Public Information in the Pricing of IPOs*
}

\author{
Einar Bakke \\ Norwegian School of Economics and Centre for Finance ${ }^{\dagger}$ \\ Tore E. Leite \\ Norwegian School of Economics \\ Karin S. Thorburn \\ Norwegian School of Economics, CEPR, and ECGI
}

September 2016

\begin{abstract}
Extant literature shows that IPO first-day returns are correlated with market returns preceding the issue. We propose a rational explanation for this puzzling predictability by adding a public signal to Benveniste and Spindt (1989)'s information-based framework. A novel result of our model is that the compensation required by investors to truthfully reveal their information decreases with the public signal. This "incentive effect" receives strong empirical support in a sample of 6,300 IPOs in 1983-2012. Controlling for the incentive effect, the positive relation between initial returns and pre-issue market returns disappears for top-tier underwriters, where the order book is held to be most informative, effectively resolving the predictability puzzle.
\end{abstract}

Keywords: IPO, underpricing, bookbuilding, public information, private information, partial adjustment

JEL Classification: G24, G32.

\footnotetext{
${ }^{*}$ We thank Sebastien Betermier, Espen Eckbo, Sturla Fjesme, Paolo Fulghieri, David Goldreich, Eva Liljeblom, Sebastian Muller, Kjell Nyborg, Tommy Stamland, Per Strömberg, Lucy White, Weidong Xu, Per Östberg, an anonymous referee, seminar participants at Aalto, BI Norwegian School of Business, Cass, K.U. Leuven/Louvain School of Management Joint Finance Workshop, Norwegian School of Economics, UC San Diego, University of Bergen, University of Stavanger, Oslo Business School, and University of Zurich, and participants at the annual conferences of the American Finance Association, European Finance Association, and Northern Finance Association, as well as the Australian Banking and Finance conference, and the Utah Winter Finance conference for valuable comments. Bakke is grateful for financial support from Browaldh Stiftelsen and the Norwegian Research Council (Leiv Ericsson). This paper was written while he visited UC San Diego and BI Norwegian Business School.

${ }^{\dagger}$ Centre for Finance at University of Gothenburg

${ }^{\ddagger}$ Corresponding author: karin.thorburn@nhh.no.
} 


\section{Introduction}

Shares in initial public offerings (IPOs) are in general sold at a fixed price, which is set after marketing the issue to investors and recording their demand. ${ }^{1}$ Despite the prior interaction with investors, the offer price typically generates a sizeable first-day return - the standard measure of underpricing. Over the period 1980-2015, the first-day return in US IPOs averaged 18\%, leaving substantial profits for investors participating in the offering. ${ }^{2}$

There is a number of alternative explanations for the underpricing in IPOs, ranging from asymmetric information to investor sentiment and conflicts of interests within integrated investment banks. ${ }^{3}$ Benveniste and Spindt (1989) provide an information-based explanation for the underpricing. In their model, investors receive underpriced shares in return for truthfully revealing their demand during the book building preceding the offering, allowing the underwriter to set a price that maximizes the issuer's proceeds. Their argument receives strong empirical support beginning with Hanley (1993). She shows that the initial return is increasing in the revision of the offer price from the mid-point of the pricing range indicated in the prospectus. It is as if investors' information is not fully priced - an empirical regularity known as the "partial adjustment" phenomenon.

While it may be rational to compensate investors for private information that helps increase the precision of the offer price, there is substantial evidence that public information also affects IPO underpricing. As shown by Loughran and Ritter (2002) and Lowry and Schwert (2004), the higher the market return leading up to the offering, the greater is the underpricing. ${ }^{4}$ This predictability of initial returns is puzzling since the public information is freely available to the underwriter and should be fully incorporated into the offer price. The extant literature has attacked this puzzle by assuming irrational behavior (Loughran and Ritter, 2002; Derrien, 2005) or an exogenous correlation between the state of the economy and the expected value of the issuer's shares to the investor (Edelen and Kadlec, 2005; Sherman, 2005). Furthermore, Leite (2007) demonstrates that public information affects the winners curse problem in the issue and in turn the issuers pricing decision.

\footnotetext{
${ }^{1}$ The auction method, most spectacularly used by Google in 2004, is an exception (Derrien and Womack, 2003; Lowry, Officer, and Schwert, 2010).

${ }^{2}$ Source: Jay Ritter at http://bear.warrington.ufl.edu/ritter/ipodata.htm

${ }^{3}$ See, e.g., Ljungqvist (2007) for a comprehensive survey of the empirical IPO underpricing literature.

${ }^{4}$ See also Logue (1973), Bradley and Jordan (2002), Benveniste, Ljungqvist, Wilhelm, and Yu (2003), Ince (2014) and Kutsuna, Smith, and Smith (2009).
} 
Our contribution is twofold. First, we endogenously derive the correlation between the public signal and the IPO underpricing in a model that preserves the information-based intuition of the Benveniste and Spindt (1989) framework. The key assumption is that the public and private signals are informative about the issuing firm's value, which in a rational Bayesian equilibrium generates a conditional correlation between the signals. Second, we perform large-sample tests of the model and find strong empirical support for its predictions.

In our model, the public information affects the equilibrium underpricing through two channels: investor demand for allocations and investor incentives to truthfully reveal their private information. We refer to the first channel as the demand effect of the public signal. Intuitively, since the public and private signals are conditionally correlated, the public information affects the distribution of investors' private signals and thus their demand for share allocations. Specifically, a positive (negative) public signal is associated with a higher (lower) likelihood of sufficient investor demand to generate underpricing.

The second channel through which the public signal affects underpricing is what we label the incentive effect: the conditional initial return necessary to induce investors to truthfully reveal their private signal. This channel is new to the literature and unique to our model. As in Benveniste and Spindt (1989), investors may misrepresent their information in an attempt to lower the offer price. However, the underwriter optimally allocates shares to investors reporting positive information and strategic false reporting may cut the investor's allocation. The likelihood that an untruthful investor receives shares in the issue depends on the public signal: it is lower (higher) for a positive (negative) signal, reducing (increasing) the incentives to report falsely. The public signal also affects the expected aftermarket value of the firm, where a positive (negative) signal reduces (increases) the marginal informational value of the private signal. Thus, to induce investors to truthfully reveal their signals, the underwriter must, ceteris paribus, underprice the issue less (more) when the public signal is positive (negative).

Through the demand effect and the incentive effect, the public signal has both a positive and a negative effect on the expected underpricing. The ultimate impact of the public signal depends on the relative magnitude of the two channels. In our setting, the informational value of a private signal is declining in the number of investors participating in the offering. Thus, when the number of investors is sufficiently large, the demand effect dominates the incentive effect and the expected 
underpricing is positively related to the public information, consistent with extant evidence.

We test our model in a sample of 6,300 US IPOs in the period 1983 to 2012 . To correct for any potential truncation of the initial returns caused by withdrawn offerings, we follow Edelen and Kadlec (2005) and use a two-step Heckman (1979) procedure. A unique and central implication of the model is that investors require higher conditional initial returns to truthfully report their private information in falling markets than in rising markets. We test this by regressing the initial IPO return on an interaction term between the private information and a dummy variable indicating that the return on the S\&P500 index leading up to the issue is positive. To capture investor private information, we use the revision in the final offer price from the initial pricing range mid-point, orthogonalized to the S\&P500 index to purge any effect of the market return on the offer price revision.

Cross-sectional regressions produce a negative and highly significant coefficient for the key interaction term. That is, the initial return associated with an offer price revision is lower when the market return is positive than when it is negative, as predicted by the model. This finding is new to the empirical literature and consistent with the incentive effect. The result is robust to the inclusion of standard control variables and the correction for self-selection, which in itself lacks statistical significance.

Like Benveniste and Spindt (1989), our model holds that investor bids contain private information about issuer valuation. Following Wang and Yung (2011), who show that the partial adjustment phenomenon is concentrated to top-tier underwriters, we split the sample according to underwriter rank. Importantly, the interaction term for the incentive effect is highly significant only in the subsample of top-tier underwriters, where the order book is held to be most informative. ${ }^{5}$ Moreover, after controlling for the incentive effect, the correlation between the first-day return and the pre-issue market return disappears, hence resolving the puzzling predictability of initial returns.

For completeness, we also show that the implications of the demand effect hold in the data. As expected, the likelihood that the initial return is positive increases with the stock market return during the book building process. The rest of the paper is organized as follows. In Section 2, we set up the model. Section 3 discusses the relation between public information and expected underpricing, as well as the key assumptions of the model. In Section 4, we describe the sample

\footnotetext{
${ }^{5}$ See, e.g., Ljungqvist (2007) and Jenkinson and Jones (2004).
} 
and report the results from our empirical tests. Section 5 concludes. All proofs are found in Appendix A.

\section{The model}

\subsection{The information structure}

We start with a firm that is about to offer its shares to outside investors through an IPO. The true value of the firm is high $G$ with probability $\alpha$ and low $B$ with probability $1-\alpha$, where $G>B$. To simplify the exposition, and with no loss of insight, we let $G=1$ and $B=0$. We also normalize the number of shares to be floated to one. All agents are risk neutral and the risk-free interest rate is zero.

There are $N \geq 2$ investors participating in the offering. Each investor $i=1, \ldots, N$ observes at a zero cost a private signal $s_{i}=\left\{g_{i}, b_{i}\right\}$, where $g_{i}$ represents positive and $b_{i}$ negative information about the firm. We may think of these investors as the underwriter's regular pool of investors and the signal $s_{i}$ as their unique knowledge about the firm as well as information about their own demand and liquidity. ${ }^{6}$ Let $n \in\{0,1, \ldots, N\}$ denote the number of investors that observe positive private signals. The precision in the private signal $s_{i}$ is the same across all investors and equals $\gamma=q\left(g_{i} \mid G\right)=q\left(b_{i} \mid B\right)$, where $q(\cdot \mid \cdot)$ and $q(\cdot)$ denote conditional and unconditional probabilities throughout. We let $\gamma>1 / 2$ to make the signal informative about the true value of the firm, so that $q\left(G \mid g_{i}\right)>q(G)>q\left(G \mid b_{i}\right)$.

Moreover, all investors observe a common public signal $s=\{g, b\}$, where $g$ represents positive and $b$ negative information. The precision in the public signal is given by $\mu=q(g \mid G)=q(b \mid B)$, where $\mu>1 / 2$ and so it is informative. We can think of the public signal as market-wide information, such as changes in aggregate demand or the business cycle, which affects the value of the firm. In the empirical analysis below, we use the stock market return during the book-building process as a proxy for the public signal.

We further assume that the signals, or more precisely the error terms, are uncorrelated con-

\footnotetext{
${ }^{6}$ Alternatively, one could assume that investors' private signals are costly and that the underwriter is able to distinguish informed from uninformed investors, and will allow only informed investors to participate in the bookbuilding process. If now the underwriter is unable to commit to compensate investors for their informational costs, then the number $\mathrm{N}$ of investors in the offering will be determined endogenously from their incentive constraint and the pricing of the issue will be the same as under our zero-cost assumption.
} 
ditional on the true value of the firm, so that $q\left(g_{i}, g \mid G\right)=q\left(g_{i} \mid G\right) q(g \mid G)$ and $q\left(g_{i}, g \mid B\right)=$ $q\left(g_{i} \mid B\right) q(g \mid B) .{ }^{7}$ By Bayes' rule, these assumptions yield the following result:

Lemma 1 The probability that an investor's private signal $s_{i}$ is positive (negative) is higher if the public signal $s$ is positive (negative) than if it is negative (positive); in other words, $q\left(g_{i} \mid g\right)>q\left(g_{i} \mid b\right)$ and $q\left(b_{i} \mid b\right)>q\left(b_{i} \mid g\right)$.

Lemma 1 implies that the distribution of investors' private signals will depend on the realization of the public signal. The positive conditional correlation follows directly from the assumption that the signals are informative about the true value of the firm. ${ }^{8}$

Let $v(n, s)$ denote the market value of the firm after it is publicly listed for a given number of positive private signals $n$. The aftermarket value is assumed to fully reflect all available information at the time of the offering. That is, $v(n, s)$ is the expected value of the firm conditional on the $n$ positive private signals observed by investors and the public signal $s$, and hence, $\partial v / \partial n>0$. With $v(n, s)$ as a conditional expectation, the marginal impact of each investor's private signal on the firm's aftermarket value is decreasing in the number $N$ of investors in the offering. Because the aftermarket value of the firm increases with the number of positive private signals, $n$ is also a measure of the demand for shares in the issue, with a higher $n$ corresponding to higher demand.

\subsection{The optimal pricing and allocation rule}

The book-building process is run by an underwriter, whose services are free of charge. The underwriter declares a pricing and allocation rule that maximizes the proceeds to the issuer. After observing the public and private signals, investors report their signal by placing a "high" or "low" bid. In equilibrium, all investors truthfully report their signals. Thus, when the underwriter sets the offer price at the end of the book-building process, he correctly anticipates the firm's value $v(n, s)$ in the aftermarket.

We assume that the underwriter is constrained to allocate at most a fraction $1 / \bar{n}$ of the issue to one investor. As a result, the issue must be distributed to at least $\bar{n}$ investors, where $0<$

\footnotetext{
${ }^{7}$ Using the normal distribution as a reference point, our informational assumptions are akin to having the true value of the firm $V$ be normally distributed with some mean $\bar{V}$ and variance $\sigma_{V}^{2}$ and letting each investor $i$ observe a signal $s_{i}=V+\epsilon_{i}$, where $\epsilon_{i}$ has a zero mean, $\operatorname{cov}\left(\epsilon_{i}, \epsilon_{j}\right)=0$ for $i \neq j$, and $\operatorname{cov}\left(s_{i}, s_{j}\right)=\sigma_{V}^{2}>0$. Similarly, for a public signal $s=V+\epsilon_{p}$, it will be the case that $\operatorname{cov}\left(\epsilon_{i}, \epsilon_{p}\right)=0$, and $\operatorname{cov}\left(s_{i}, s\right)=\sigma_{V}^{2}$.

${ }^{8}$ That is, $q\left(g_{i} \mid G\right)>1 / 2, q(g \mid G)>1 / 2, q\left(b_{i} \mid B\right)>1 / 2$, and $q(b \mid B)>1 / 2$.
} 
$\bar{n} \leq N$. Since all private signals have the same precision, investors with identical bids receive equal allocations. A central insight of Benveniste and Spindt (1989) is that, to maximize expected proceeds, it is optimal to maximize (minimize) the fraction of the issue allocated to investors who submit high (low) bids. This implies that investors bidding low will be allocated shares only if the number $n$ of investors placing high bids falls below $\bar{n}$. Hence, if $n \geq \bar{n}$, investors submitting high bids will each receive $z_{H}(n) \equiv 1 / n$ of the issue. If instead $n<\bar{n}$, investors bidding high will each receive $1 / \bar{n}$ of the issue and investors who bid low will each receive $z_{L}(n) \equiv\left(\frac{1}{N-n}\right)\left(1-\frac{n}{\bar{n}}\right)$.

Let $p_{H}(n, s)$ denote the offer price when $n \in[\bar{n}, N]$, so the issue is allocated exclusively to investors submitting high bids. Let further $p_{L}(n, s)$ denote the offer price when $n \in[0, \bar{n})$, i.e., the states in which a fraction $1-\frac{n}{\bar{n}}$ of the issue is allocated to investors with low bids. We refer to the pricing for the former as an upward revision in the offer price (relative to the initial range) and that of the latter as a downward revision. We assume that the underwriter is committed to price the issue so that it is never overpriced in expectation.

Let us next consider investors' incentives to truthfully reveal their private signals. An investor with a bad signal has a negative expected payoff from submitting a high bid and therefore no incentive to report falsely. Instead, we need to worry about the incentives of investors with positive private signals. These investors may benefit from falsely reporting their signals as negative in order to lower the issue price. Indeed, this possibility ensures that investors with good information earn strictly positive informational rents in the IPO. The underwriter prices and allocates the issue to minimize the informational rents of these investors, while at the same time inducing them to report truthfully.

The expected payoff to an investor $i$ with a positive private signal $g_{i}$ from submitting a low bid is equal to

$$
\begin{aligned}
\hat{U}_{L}(s) & =\sum_{n=0}^{\bar{n}-1} z_{L}(n) \hat{q}\left(n \mid g_{i}, s\right)\left[v(\hat{n}+1, s)-p_{L}(\hat{n}, s)\right] \\
& =\sum_{n=0}^{\bar{n}-1} z_{L}(n) \hat{q}\left(\hat{n} \mid g_{i}, s\right)[v(\hat{n}+1, s)-v(\hat{n}, s)]
\end{aligned}
$$

where $\hat{q}\left(\hat{n} \mid g_{i}, s\right)$ is the probability that $\hat{n}$ of the other $N-1$ investors receive positive private signals conditional on $g_{i}$ and the public signal $s$. Given investor $i$ 's low bid, $\hat{n}$ is the number of high bids 
and $\hat{n}+1$ is the total number of positive private signals. The payoff $\hat{U}_{L}(s)$ represents investor $i$ 's informational rents in the offering. It is strictly positive and is her reservation payoff.

The underwriter must price and allocate the issue so as to minimize $\hat{U}_{L}(s)$. This yields allocations of $z_{L}(s)$ and $z_{H}(s)$, as explained above. Moreover, whenever investors with low bids are allocated shares, the underwriter must price the offering as high as possible conditional on the revealed information. This implies that $p_{L}(\hat{n}, s)=v(\hat{n}, s)$ and the IPO is not underpriced when the offer price is revised downward.

In equilibrium, investors with positive private signals submit high bids. The expected payoff to an investor $i$ with a private signal $g_{i}$ from submitting a high bid is

$$
\hat{U}_{H}(s)=\sum_{\hat{n}=\bar{n}-1}^{N-1} z_{H}(\hat{n}+1) \hat{q}\left(\hat{n} \mid g_{i}, s\right)\left[v(\hat{n}+1, s)-p_{H}(\hat{n}+1, s)\right] .
$$

To induce truthful reporting, $\hat{U}_{H}(s)$ must be equal to or exceed the expected payoff $\hat{U}_{L}(s)$ from falsely bidding low. Therefore, to minimize investors' rents, the underwriter will price the issue so that investors with positive signals are indifferent between bidding high and low, which implies that

$$
\hat{U}_{H}(s)=\hat{U}_{L}(s)
$$

This incentive condition, however, applies when $n \geq \bar{n}$ and there is hence $n \in[\bar{n}, N]$ prices to be solved for. We resolve this indeterminacy by setting $p_{H}(n, s)=p_{H}(s)$, so that $p_{H}(s)$ is determined uniquely from Eq. (3). Thus, when the offer price is revised upward, the underwriter always prices the IPO at $p_{H}(s)$. This feature of the model is discussed in Section 3.2 below. It follows from $\hat{U}_{L}(s)>0$ that the IPO is underpriced in expectation when $n \geq \bar{n}$.

To establish underpricing, we compare the IPO price $p_{H}(s)$ to the firm's expected aftermarket value $v_{H}(s)$ conditional on $n \geq \bar{n}$, which is given by

$$
v_{H}(s)=\frac{\sum_{n=\bar{n}}^{N} q(n \mid s) v(n, s)}{\sum_{n=\bar{n}}^{N} q(n \mid s)}
$$

The IPO is underpriced if $v_{H}(s)>p_{H}(s)$. A comparison of $v_{H}(s)$ and $p_{H}(s)$ is, however, complicated by the fact that the latter is solved from Eq. (3). That is, $p_{H}(s)$ is determined from a conditional allocation-weighted probability distribution, while $v_{H}(s)$ is determined from an uncon- 
ditional equally-weighted probability distribution. The following equivalence result simplifies this comparison and is useful for the proofs in the Appendix.

Lemma 2 The allocation-weighted expectation over $N-1$ private signals conditional on $g_{i}$ is equivalent to the unconditional expectation over $N$ signals. In other words,

$$
\sum_{\hat{n}=\bar{n}-1}^{N-1} \frac{1}{\hat{n}+1} \hat{q}\left(\hat{n} \mid g_{i}, s\right) v(\hat{n}+1)=\frac{1}{N} \sum_{n=\bar{n}}^{N} q(n \mid s) v(n)
$$

and

$$
\sum_{n=0}^{\bar{n}-1} \frac{1}{N-n} \hat{q}\left(n \mid g_{i}, s\right) v(n)=\frac{q\left(g_{i} \mid G\right)}{N} \sum_{n=0}^{\bar{n}-1} q(n \mid s) v(n) .
$$

Lemma 2 allows $\hat{U}_{H}(s)$ and $\hat{U}_{L}(s)$ to be expressed in the following way:

$$
\begin{aligned}
\hat{U}_{H}(s) & =\frac{1}{N} \sum_{n=\bar{n}}^{N} q(n \mid s)\left[v(n, s)-p_{H}(s)\right] \\
& =\frac{1}{N} U_{H}(s)
\end{aligned}
$$

and

$$
\begin{aligned}
\hat{U}_{L}(s) & =\frac{1}{N} q\left(g_{i} \mid G\right) \sum_{n=0}^{\bar{n}-1} q(n \mid s)\left(1-\frac{n}{\bar{n}}\right)[v(n+1, s)-v(n, s)] \\
& =\frac{1}{N} U_{L}(s) .
\end{aligned}
$$

The IPO price $p_{H}(s)$ is now determined from $U_{H}=U_{L}$, which gives

$$
p_{H}(s)=v_{H}(s)-\frac{U_{L}(s)}{Q_{H}(s)}
$$

where $Q_{H}(s) \equiv \sum_{n=\bar{n}}^{N} q(n \mid s)$ is the probability of an upward revision in the offer price. Since $U_{L}>0$, it follows that $v_{H}(s)>p_{H}(s)$ and the IPO is underpriced.

We have now established that the offering is underpriced when it is allocated only to investors with positive signals and otherwise priced at its expected aftermarket value. The underpricing represents a partial adjustment of the offer price to the private information uncovered during the 
book-building process, leaving a profit for investors who submit high bids. As the firm starts trading at its aftermarket price, the initial return $r(s)$ conditional on an upward revision in the offer price is given by

$$
r(s)=\frac{v_{H}(s)}{p_{H}(s)}-1
$$

The expected initial return is thus

$$
\operatorname{Er}(s)=r(s) Q_{H}(s)
$$

which is the product of the conditional initial return $r(s)$ and the probability $Q_{H}(s)$ of an upward revision, both conditional on the public signal $s$.

The analysis so far has established that IPOs are expected to be underpriced in order to induce investors to truthfully report their private information, similar to Benveniste and Spindt (1989). In the next section, we go beyond this standard argument and examine the relation between the public information and underpricing.

\section{Public information and underpricing}

\subsection{Pricing in the presence of a public signal}

As shown in Eq. (9), the expected initial return $\operatorname{Er}(s)$ is the product of the conditional initial return and the probability that the issue is underpriced. A key contribution of this paper is the insight that the public signal affects the expected initial return through both $r(s)$ and $Q_{H}(s)$, as discussed next.

Proposition 1 (The incentive effect) The initial return conditional on an upward revision in the offer price is negatively related to the public signal s, so that $r(g)<r(b)$.

Proposition 1 shows that the conditional initial return is negatively related to the public signal. To understand this result, which we label the incentive effect, note that the public signal affects investors' incentives in three ways. First, because the private and public signals are conditionally correlated, the probability of a downward offer price revision is lower for a positive than a negative 
public signal. It follows that the likelihood for an investor to receive underpriced shares after falsely bidding low is lower, as is his expected payoff, when the public signal is good.

Second, the marginal impact of a positive private signal on the firm's aftermarket value is declining in the public signal. The payoff to an investor receiving underpriced IPO shares after reporting falsely is therefore lower for a positive than a negative public signal, reducing the incentive to bid low. Third, the conditional correlation between the private and public signals implies that the probability $Q_{H}(s)$ of an upward revision in the offer price is higher for a positive than a negative public signal. This means that the likelihood for an investor reporting truthfully to receive underpriced shares is higher for a positive public signal. Hence, the expected payoff from truth-telling is higher and the underwriter can increase the IPO price without jeopardizing the investor's incentives to bid high.

The incentive effect holds that the public signal has a negative impact on the expected initial return through investors' incentives to truthfully reveal their information. However, as shown in Eq. (9), the expected initial return is also affected by the public signal through the probability $Q_{H}(s)$ that there is sufficient demand for the issue to be underpriced.

Proposition 2 (The demand effect) The probability that the IPO is underpriced is positively related to the public signal, i.e., $Q_{H}(g)>Q_{H}(b)$.

As stated in Proposition 2, the likelihood that the issue is underpriced is higher for a positive than a negative public signal. This channel, which we label the demand effect, follows directly from Lemma 1. Specifically, since the public and private signals are conditionally correlated, the probability of an upward revision in the offer price (so the issue is underpriced) is higher for a positive public signal.

Through the two channels in our model, public information has both a positive and a negative impact on the expected underpricing. We next show that the demand effect will dominate as long as a sufficiently large number of investors participate in the IPO.

Proposition 3 When the number $N$ of investors in the issue is sufficiently large, the demand effect strictly dominates the incentive effect and the expected initial return is positively related to the public signal. 
The intuition of Proposition 3 relies on the declining impact of an investor's private signal on the firm's aftermarket value as the number of investors in the issue increases. Specifically, as $N$ increases, the investor's potential payoff from falsely bidding low $v(n+1, s)-v(n, s)$ conditional on an allocation $(n<\bar{n})$ drops. This decline in informational rents reduces the amount of underpricing required to induce truthful revelation. Thus, an increase in $N$ decreases the relative importance of the incentive effect. Once the number of investors in the issue is sufficiently large, the demand effect strictly dominates the incentive effect. The public signal is then positively related to the expected underpricing, consistent with extant evidence.

\subsection{Discussion of key assumptions}

Our model extends the original work by Benveniste and Spindt (1989). By adding a public signal, we show that public information affects the initial return through two different channels: investors' incentives to report truthfully and the likelihood of sufficient demand to induce underpricing. While most of the basic setup is the same as in the original model, we make two major alterations, which are discussed in this section.

The first alteration is to specify the firm's aftermarket value as an unbiased expected value conditional on investors' private signals and the public signal, consistent with strong-form market efficiency. This contrasts with the original setup, where the aftermarket value is an additive function of investors' private signals. ${ }^{9}$ By modeling the aftermarket value $v(n, s)$ as a conditional expectation of firm value, the marginal impact of each private signal on the aftermarket value is decreasing in the number of investors with positive signals. This specification is necessary for the incentive effect to hold for an unrestricted set of parameter values, as in Proposition 1 above. It is also necessary for Proposition 3 to come through.

Our way of modelling the valuation impact of private signals is consistent with the market microstructure literature, in which investors' private information is reflected in the stock price through the trading process (Kyle, 1985). A similar assumption in Chen and Wilhelm (2008) leads early-stage investors to bid aggressively in the IPO aftermarket, as the value of their information declines when additional informed investors enter the market. Note also that allowing investors

\footnotetext{
${ }^{9}$ In Benveniste and Spindt (1989), each private signal "has an equal (absolute) marginal impact on the stock's value" (p.347).
} 
to trade on their private information in the aftermarket, as in Busaba and Chang (2010), only strengthens the incentive effect.

The second alteration is to fix one price $p_{H}(s)$ across all underpriced states $n \in[\bar{n}, N]$, in which the issue is allocated exclusively to investors who submit high bids. Because the amount

of underpricing is determined by the payoff $\hat{U}_{L}(s)$ from falsely submitting a low bid, the state-bystate underpricing across states $n \in[\bar{n}, N]$ is indeterminate and hence arbitrary. We resolve this indeterminacy by having the underwriter set the same price $p_{H}(s)$ independently of $n \in[\bar{n}, N]$. A similar indeterminacy is present in Benveniste and Spindt (1989) as well. Unlike us, however, they do not need to specify the exact prices across these states, but only that these are the states in which the IPO is underpriced.

An alternative approach, which we used in earlier versions of this paper, is to allocate all underpricing to state $n=N$ combined with allocating shares to low bidders only if all investors submit low bids (when $n=0$ ). This modelling strategy is supported by an assumption that the underwriter may allocate the entire issue to one investor (i.e., $\bar{n}=1$ ). The alternative approach resembles that used by Biais and Faugeron-Crouzet (2002) in a comparative analysis of various selling mechanisms for unseasoned shares. We chose the present approach as it is more general, while still permitting analytical solutions and yielding identical results.

\section{Empirical tests of the model}

In our model, the public signal has both a positive and a negative effect on the expected underpricing. Prior studies, which show that the initial return increases with the pre-issue market return, document the combined effect of the two channels. In this paper, we design an empirical testing strategy which allows us to examine each channel separately.

The incentive effect holds that the public signal affects the expected underpricing through investors' incentives to report truthfully. It the context of the literature, it implies that the underpricing associated with a given offer price revision is greater in falling markets than in rising markets. This empirical prediction is new to the literature and unique to our model. The demand effect, on the other hand, channels the impact of the public signal through the probability that the issue is underpriced. It implies that the likelihood of the underwriter underpricing the IPO 
increases with the pre-issue market return.

In the cross-sectional analysis below, we test each of the two channels in our model and show that the predictability of the initial return to the market return disappears for top-tier underwriters once we control for the incentive effect. Before presenting the cross-sectional analysis, however, we'll first introduce the sample, provide a brief univariate analysis, analyze the probability of completing the IPO, and verify that partial adjustment exists in our data.

\subsection{Sample selection, description and key variables}

We start by selecting all 13,462 U.S. IPOs in the period 1970 to 2012 from the Global New Issues database in Thompson Financial's SDC. To identify book-built IPOs, we restrict the sample to the 8,825 cases with a positive spread between the high and low filing price. SDC does not report a filing range prior to 1981, so this restriction effectively eliminates all offerings in the 1970s.

We require the IPO firms to have a filing midpoint of at least $\$ 5$ per share, be matched with CRSP and be listed on NYSE, AMEX or Nasdaq. All unit offerings, real estate investment trusts, financial institutions, American Depository Receipts, and closed-end funds are eliminated. We further restrict the sample to firms with a founding year in the Field-Ritter founding data set and a lead underwriter rank in the Ritter underwriter ranking data set, and require the completed IPOs to trade by the 42 nd trading day after the public listing. ${ }^{10}$ These selection criteria produce a final sample of 6,301 IPOs filed between 1983 and 2012, of which 5,369 are completed and 932 are withdrawn.

Table 1 reports the number of cases, initial returns and pre-issue market returns by year. The initial return is defined as $I R 1=p_{1} / p_{0}-1$, where $p_{1}$ is the firm's closing price on the first day of trading and $p_{0}$ is the final offer price, winsorized at $200 \%$. In the empirical analysis below, we use $I R 1$ as a proxy for the underpricing in the IPO. ${ }^{11}$ The market return (Public) is the return on the S\&P500 index over the 42 trading days preceding the IPO issue date. We select this window to match the typical registration period in our sample. As shown in column (1), a majority of the sample firms (58\%) file to go public in the 1990 s, while $25 \%$ file in the 2000 s and $17 \%$ file in the 1980s.

\footnotetext{
${ }^{10}$ The founding year and lead underwriter rank is from Jay Ritter's web page at the University of Florida.

${ }^{11}$ In unreported regressions, where we use the first-month return as a proxy for the underpricing, the inferences are qualitatively unchanged.
} 
The next four columns of Table 1 present statistics for the 5,369 completed IPOs. As reported in column (3), the average initial return is $19.7 \%$, with a peak of $67 \%$ and $53 \%$ in 1999 and 2000 , respectively. Moreover, the average market return preceding the issue is $2.5 \%$ (column (4)) and it is positive for $72 \%$ of the IPOs (column (5)). Notice that even in the hot issue year of 1999, onequarter of the completed IPOs were preceded by negative market returns. The last four columns of Table 1 present statistics for the 932 withdrawn IPOs. As shown in column (7), 15\% of the IPOs in our sample are withdrawn. Not surprisingly, the withdrawn IPOs are preceded by a lower market return of on average $0.9 \%$ (column (8)). Yet, the pre-issue market return is positive for as many as $60 \%$ of the withdrawn IPOs (column (9)).

A test of our model requires a measure for the private information uncovered by the underwriter through the book-building process. We follow Hanley (1993) and rely on the revision in the final offer price: Revision $=p_{0} / p_{\text {mid }}-1$, where $p_{\text {mid }}$ is the midpoint of the pricing range in the initial SEC filing (the "filing range"). Some of the decision to revise the offer price may, however, originate in market-wide information reaching the underwriter during the registration period. We therefore purge any effect of the stock market return from the offer price revision.

To decide on a model for orthogonalizing Revision and Public, we first examine how investment banks revise the offer price within and outside of the filing range. Panels A and B of Table 2 show the frequency distribution in number and percent, respectively, of the price revision, conditional on the direction and magnitude of Revision. As shown in Panel B, almost half of the IPOs are priced outside of the range: $25 \%$ below the minimum price (column (1)) and $23 \%$ above the maximum price (column (7)). Moreover, another $30 \%$ of the IPOs are priced at the filing range endpoints: $14 \%$ at the minimum (column (2)) and $16 \%$ at the maximum (column (6)). Thus, only $22 \%$ of the IPOs are priced strictly inside the filing range, of which half are not revised at all (11\%, column (4)). As it turns out, the vast majority of IPOs have a $\$ 2$ wide filing range (midpoint $+/-\$ 1$ ) and the within range price revisions cluster on zero, $+/-50$ cents, and $+/-\$ 1$ (the endpoints).

Panel $\mathrm{C}$ of Table 2 reports the corresponding conditional mean price revision. The average value of Revision for IPOs priced above and below the range is $+21 \%$ and $-22 \%$, respectively, while it is $+/-8 \%$ for IPOs priced at the filing range endpoints. The fact that $30 \%$ of the IPOs are priced at the endpoints, combined with the much larger revisions for IPOs priced outside of the range, indicate that within-range price revisions may be determined differently from offer prices set 
outside of the range.

In order to allow for the use of different pricing algorithms for offer prices inside and outside of the range, we define Private as the residual $\epsilon$ from the following regression:

$$
\text { Revision }=\alpha+\beta_{1} * \text { Public }+\beta_{2} * \text { Public } * \text { WithinRange }+\beta_{3} * \text { WithinRange }+\epsilon .
$$

This specification holds that any information in the price revision beyond that directly attributable to the stock market is private. ${ }^{12}$ Ordinary Least Squares (OLS) estimation of Eq. (10) generates coefficient estimates of $\beta_{1}=1.01$ and $\beta_{2}=-0.84$. This suggests that IPOs priced outside of the filing range tend to be updated one-to-one with the contemporaneous stock-market movement. In contrast, IPOs priced within the range, where the association between Private and Public is given by $\beta_{1}+\beta_{2}=0.17$, are typically left relatively unadjusted for stock-market returns. Panel D of Table 2 shows the conditional mean of Private across the different categories of price revisions. The average value of Private is $+/-8 \%$ for IPOs priced at the filing range endpoints and $+23 \% /-21 \%$ for IPOs priced outside of the filing range.

Wang and Yung (2011) find evidence of more frequent filing of price revisions by reputable investment banks and suggest that the partial adjustment phenomenon is attributable to the toptier underwriters. As discussed in Ljungqvist (2007), this is consistent with the difference in results found by Cornelli and Goldreich $(2001,2003)$ and Jenkinson and Jones (2004). The former examine the order book of a top-tier underwriter and show that more informative bids-limit-order bids, bids received early, and revised bids - receive greater allocations. Jenkinson and Jones (2004), however, find no such evidence for the order book of a lower-tier underwriter and suggest that there are important differences in the informativeness of the order book between top-tier and lower-tier underwriters.

Since our framework requires informative investor bids, we follow Carter and Manaster (1990) and split our sample into IPOs where the highest-ranked lead underwriter is a top-tier underwriter $(\mathrm{rank}=9)$ versus a lower-tier underwriter $(\mathrm{rank}<9)$. Half of the completed IPOs in our sample have at least one top-tier lead underwriter, while the remaining sample firms use lead underwriters with a rank below 9 . Given systematic differences in the informativeness of the order book, the incentive

\footnotetext{
${ }^{12}$ Although the price revision has been shown to vary with certain offer characteristics, these are known when the initial filing range is set and do not represent new information in our setting.
} 
effect should be strongest for the subsample of IPOs sold by top-tier underwriters. ${ }^{13}$

The offer price revisions in our data are consistent with top-tier underwriters receiving informative bids and lower-tier underwriters failing to do so. As in Wang and Yung (2011), we find that the mean and standard deviation of Revision are higher for top-tier underwriters. Moreover, the distribution of Revision for the top-tier underwriters is almost twice as positively skewed, consistent with investors being rewarded for positive information. As reported in Panel B of Table 2 , top-tier underwriters price $29 \%$ of the IPOs above the filing range, compared to $16 \%$ for the lower-tier underwriters.

\subsection{Univariate analysis}

We first examine the relation between the first-day return and the pre-issue market return in the univariate. Table 4 shows the average initial return (IR1) for the subsample of 4,184 completed IPOs that are priced outside of, or at the endpoints of, the filing range. ${ }^{14}$ The IPOs are split by falling $\left(\right.$ Public $\left._{N E G}\right)$ and rising $\left(\right.$ Public $\left._{P O S}\right)$ pre-issue stock markets, where the subscripts $N E G$ and POS indicate that the variable Public is $\leq 0$ and $>0$, respectively.

In our model, the investment bank underprices the offering only when there is an upward price revision, i.e., when $n \geq \bar{n}$ investors receive a positive private signal and bid high. To capture the demand states, the table further separates the issues into positive (Private $P O S$ ) and negative $\left(\right.$ Private $\left._{N E G}\right)$ private information, where Private is the price revision adjusted for the pre-issue market return according to Eq. (10) above. The first three columns present the total, while columns (4)-(6) and (7)-(9) show the subsamples of IPOs sold by top-tier and lower-tier underwriters, respectively. Variable definitions and data sources are listed in Table 3.

Panel A addresses the incentive effect. Starting with the full sample, the average initial return is substantially higher when investor demand is high. For example, in column (1), IR1 is $44 \%$ for Private $_{P O S}$ and only $4 \%$ for Private $_{N E G}$, consistent with underwriters rewarding investors for private information. Moreover, comparing columns (1) and (3), the average initial return is lower in

\footnotetext{
${ }^{13}$ Alternatively, large IPOs may attract more interest from sophisticated institutional investors, increasing the informativeness of the order book. In our sample, however, the large IPOs always have top-tier lead underwriters. Our key empirical results are qualitatively unchanged if we split the sample by size rather than underwriter quality.

${ }^{14}$ In practise, price revisions are discrete and have to be done at least in tick size increments. Even if there is no private information and Revision is correctly adjusted for the market return, it is unlikely that $\epsilon=0$ in Eq. (10) for small price revisions. Thus, we exclude 1,185 strictly within-range price revisions from the univariate comparison.
} 
falling markets than in rising markets ( $19 \%$ vs. $23 \%$, with $\mathrm{p}<0.01$ for the difference). This positive correlation between initial returns and market returns is the predictability puzzle that our model sets out to explain.

The incentive effect, however, implies a negative relation between the conditional initial return and market return for issues in high demand. As shown in Panel A, this conjecture holds for Private $_{P O S}$, where $I R 1$ is significantly higher in falling than rising markets (44\% vs. $\left.38 \%, \mathrm{p}<0.05\right)$.

Panel B of Table 4 addresses the demand effect, which predicts that the likelihood of underpricing increases with the market return. As reported, the fraction of IPOs with positive initial return $(\operatorname{IR} 1>0)$ is significantly lower in falling markets. For example, $68 \%$ of all IPOs are underpriced in falling markets vs. $78 \%$ in rising markets, with $\mathrm{p}<0.001$ for the difference, as predicted.

We next turn to the subsamples based on underwriter quality. As shown in Panel A, the initial return is positively associated with underwriter rank. For example, when the market return is positive, the first-day return averages $28 \%$ for IPOs sold by top-tier underwriters (column (6)) and $17 \%$ for lower-tier underwriters (column (9)).

Focusing on the top-tier underwriters (columns (4) to (6)), the difference in average initial return across falling and rising markets is significantly negative $(-11 \%, \mathrm{p}<0.01)$ for issues in high demand, consistent with the incentive effect. Panel B further shows that the fraction of underpriced IPOs does not vary with market conditions, as if the demand effect is weak. Combined, this suggest that the conditional initial return - the incentive channel-drives the difference in $I R 1$ for top-tier underwriters.

For lower-tier underwriters, however, the difference in $I R 1$ across falling and rising markets is now positive $(5 \%, \mathrm{p}<0.05)$ for issues in high demand. Moreover, the fraction of underpriced IPOs is somewhat lower for Private $_{N E G}$ than for Private $_{P O S}(91 \%$ vs. $94 \%, \mathrm{p}<0.10)$. Thus, it appears as if the incentive effect is relatively weak for the lower-tier underwriters, consistent with a less informative order book.

Finally, Panel $\mathrm{C}$ of Table 4 shows the number of observations across the different subsamples and illustrates the conditional correlation between the private and public signals in our model. The fraction of IPOs with high demand $\left(\right.$ Private $\left._{P O S}\right)$ is significantly higher in rising than falling markets (54\% vs. 38\%). Conversely, the fraction of IPOs with low demand (Private PEG $_{\text {) }}$ is significantly lower in rising markets $\left(46 \%\right.$ vs. $62 \%$ for Public $\left.{ }_{N E G}\right)$. This pattern, which supports 
Lemma 1, holds across all underwriter types.

Overall, the univariate statistics in Table 4 are consistent with the empirical implications of our model. First, while the average initial return and the market return are positively associated in the sample at large, they are negatively related for IPOs in which the incentive effect is expected to be strong, i.e., issues in high demand sold by top-tier underwriters. Second, the fraction of IPOs with a positive initial return is lower when the stock market is falling, as implied by the demand effect. Third, the likelihood that the final offer price is adjusted upward - tantamount to high investor demand - is higher when markets are rising, consistent with a conditional correlation between the private and public signals.

\subsection{Withdrawal of the IPO}

To empirically test our model, we regress the initial return on the pre-issue market return in various specifications capturing the implications of the incentive and demand effects. Note first that issuers may choose to withdraw the IPO when the market return is low (Busaba, Benveniste, and Guo, 2001; Benveniste, Ljungqvist, Wilhelm, and Yu, 2003). The decision to withdraw the IPO leads to a truncation of the sample of initial returns and the coefficients from an ordinary least squares (OLS) regression may be biased. To correct for this truncation in the observed underpricing, we follow Edelen and Kadlec (2005) and use a two-step Heckman (1979) procedure.

This subsection describes the first step of the Heckman prodedure, in which the probability of completion (versus withdrawal) is estimated. Table 5 reports the coefficient estimates from probit regressions, where column (1) uses the full sample of 6,301 IPOs and columns (2) and (3) present the results for the two subsamples defined by underwriter rank.

The explanatory variables are issue and market characteristics that previously have been shown to affect the withdrawal decision. The first two variables are the pre-issue stock-market return in rising and falling markets: Public ${ }^{*}$ Public $_{P O S}$ and Public $^{*}$ Public $_{N E G}$, respectively. Moreover, Underwriter Count is the number of underwriters in the offering, Amount Filed is log of the dollar value of the issue, and Underwriter Rank is the Carter and Manaster (1990) rank of the highestranked lead underwriter.

The next three variables describe the current state of the IPO markets, measured across all IPOs over the 42 trading days preceding the issue: Spillover Revision is the average offer price revision 
(Revision) ortogonalized to Public; Spillover IR1 is the average initial return (IR1) ortogonalized to Public and Spillover Revision; and Spillover Withdrawn is the number of withdrawn IPOs during the same period. Specifically, we use the residuals from the regressions Revision $=\alpha+\beta *$ Public $+\epsilon$ and $I R 1=\alpha+\beta_{1} *$ Public $+\beta_{2} *$ Spillover Revision $+\epsilon$, respectively.

Starting with column (1), the regression results are consistent with prior studies. The likelihood that the offering is successful decreases with issue size and increases with the number and rank of underwriters marketing the IPO. The probability of completing the issue also depends on the state of the IPO markets, where the number of withdrawn IPOs and the first-day return of recent IPOs both have a negative effect on the completion rate. Controlling for the performance of recent IPOs, the completion likelihood is further decreasing in the pre-issue stock market return, Public, and it is more sensitive to the market return in falling than rising markets.

Turning to columns (2) and (3), most of the inferences hold across underwriters of different quality. The exception is the coefficient for Public ${ }^{*}$ ublic $_{P O S}$, which is negative and significant for lower-tier underwriters only. That is, for top-tier underwriters, the completion likelihood is independent of the pre-issue market return when stock markets are rising.

We use the probit estimates from these first stage regressions to compute the Inverse Mill's ratio for each observation. The inclusion of the Inverse Mill's ratio in the second-step regressions helps correct for the self-selection in the truncated sample of initial returns.

\subsection{Verifying Partial Adjustment to Public Information}

Before examining the implications of our model, we first verify that the positive relation between the initial return and the pre-issue market return found by others also hold in the cross-section for our sample. Table 6 reports the coefficient estimates from OLS regressions for the initial return, IR1. The explanatory variables in column (1) are the two main variables of interest, Public and Private, as well as the Inverse Mill's ratio from Table 5.

Column (2) adds firm and issue characteristics such as firm age (Age), Underwriter Rank, Amount Filed, the percent of the offered shares newly issued by the firm (Primary), and dummy variables indicating that the firm is in the high-tech industry (High Tech), backed by a venture capital firm ( $V C)$, and listed on Nasdaq (Nasdaq). Column (3) further includes Spillover IR1 and Spillover Revision, both capturing the current state of the IPO markets. Finally, columns 
(4) and (5) split the sample by underwriter rank. Standard errors are clustered by Fama-French 49 industry.

As shown in Table 6, the coefficients for Private and Public are positive and statistically highly significant $(\mathrm{p}<0.001)$ in all regression models. The former is consistent with underwriters leaving money on the table for investors submitting informed bids, as in Benveniste and Spindt (1989)'s information-based equilibrium. The latter is the puzzle of partial adjustment to public information that our model sets out to explain.

Note that the Inverse Mill's ratio is insignificant in columns (2)-(4), when the control variables are included. This suggests that the truncation caused by withdrawals does not bias the coefficient estimates in the regular OLS. While not shown here, the coefficient estimates are largely unchanged when we exclude the Inverse Mill's ratios from the regressions. Edelen and Kadlec (2005) also report an insignificant coefficient for the Inverse Mill's ratio and a significantly positive coefficient for the market return, indicating that the Heckman correction itself fails to explain the partial adjustment to public information. Moreover, several of the control variables are significant. The initial return is increasing in the average initial return and price revision of recent IPOs. Also, for the subsample of IPOs sold by top-ranked underwriters, the initial return decreases in firm age and tends to be higher for issuers backed by a venture capitalist.

\subsection{Tests of the incentive effect}

Having established a positive relation between underpricing and pre-issue market return in our sample, we next turn to tests of the incentive effect. A central prediction of our model is that, ceteris paribus, investors require less underpricing to truthfully report their information in rising markets than in falling markets. We test this prediction by regressing the initial return on our proxy for private information, separated by negative and positive market returns. Specifically, we run the following regression:

$$
I R 1=\gamma+\beta_{1} \text { Public }+\beta_{2} \text { Private }+\beta_{3} \text { Private } * \text { Public }{ }_{P O S}+e .
$$

The interaction variable Private $*$ Public $_{P O S}$ hence captures the difference in the impact of private information on the initial return in rising vs. falling markets. Our model predicts that $\beta_{3}<0$. 
Table 7 reports the coefficient estimates from OLS regressions of Eq. (11) and has a similar structure as Table 6. Starting with the full sample (columns (1)-(3)), Public and Private again both generate positive and highly significant $(\mathrm{p}<0.01)$ coefficients in all regression specifications, consistent with partial adjustment. Turning to the interaction term Private*Public $P O S$, it enters with a significantly $(\mathrm{p}<0.05)$ negative coefficient in all three regression specifications. As predicted by our model, the underpricing associated with a given price revision is smaller in rising markets than in falling markets. In contrast, Sherman (2005) proposes that investors' opportunity cost of becoming informed increases with the market return. Her model thus predicts $\beta_{3}>0$, which is rejected by our evidence.

As discussed above, the incentive effect requires an informative order book. To the extent that high-quality underwriters receive more informative bids, the incentive effect should be strongest for these underwriters. Hence, to exploit potential differences in order book informativeness, columns (4) and (5) split the sample by underwriter rank.

Importantly, the interaction term Private $^{*}$ Public $_{P O S}$ generates a negative and highly significant $(\mathrm{p}<0.001)$ coefficient for top-tier underwriters (column $(4))$. It is as if top-tier underwriters compensate investors more for private information in falling markets than in rising markets, as implied by the incentive effect. Moreover, the coefficient for Private is higher for IPOs sold by top-tier than lower-tier underwriters (1.10 vs. 0.40, significantly different at the $1 \%$ level). It appears that investors on average receive higher compensation for their information in issues sold by top-tier underwriters, consistent with a more informative order book.

Note also that the coefficient for Public becomes insignificant when Private*Public $P O S$ is included in column (4). That is, for the subsample of top-tier underwriters, the positive relation between the initial return and the market return disappears after controlling for the incentive effect. Our model is thus able to successfully explain the puzzling partial adjustment to public information for the subsample of top-tier underwriters, where the order book is held to be most informative. Cornelli and Goldreich (2003) similarly show that the underwriter, in setting the issue price, relies on the reaction in investor bids to public information rather than the public information itself.

Column (5) of Table 7 shows the regression estimation for the subsample of lower-tier underwriters. Here, the initial return increases not only with Public and Private, but also with 
Private $^{*}$ Public ${ }_{P O S}$ - something that our model is neither designed to nor able to explain. It is, however, consistent with Derrien (2005), who shows that both IPO prices and initial returns increase with investor demand during the internet bubble.

In sum, the implications of the incentive effect generated by our model are borne out in the data: the underpricing associated with an offer price revision tends to be lower when the stock market drops during the book building period than when it rises. This is consistent with underwriters adjusting the issue price more in response to investors' information when publicly available information is negative. The effect is concentrated to IPOs sold by top-tier underwriters, where the orderbook has been shown to be more informative - a necessary condition for the informationbased argument by Benveniste and Spindt (1989) to hold. Importantly, when controlling for the incentive effect, the positive relation between the initial return and the market return disappears in the subsample of top-tier underwriters, effectively resolving the puzzle of partial adjustment to public information.

\subsection{Tests of the demand effect}

For completeness, we also perform tests of the demand effect, which predicts a positive correlation between the market return and the likelihood that the IPO is underpriced. Table 8 reports the coefficient estimates from probit regressions for the likelihood that the initial return is positive $\left(I R 1_{P O S}\right)$. The regression model includes our standard control variables and standard errors are clustered by Fama-French 49 industry. The first four columns use the full sample of completed IPOs, while the last two columns separate the IPOs by underwriter rank.

Note first that, consistent with the demand effect, the likelihood that the issue is underpriced increases with Public and, in columns (2) and (4), with the dummy variable Public $P O S(\mathrm{p}<0.001)$. Focusing on the last two columns, the coefficient for Public is greater for lower-tier underwriters than for top-tier underwriters (4.9 vs. 3.2, $<<0.001$ for the difference), suggesting that the demand effect is stronger for lower-tier underwriters.

The variable Private also produces a positive and significant coefficient $(\mathrm{p}<0.001)$ in all regression models. That is, the greater the investor demand, the more likely is the issue to be underpriced. This is consistent with our model, where the offer is underpriced in the high-demand state.

Finally, several of the control variables generate significant coefficients. In the full sample of 
completed IPOs, the likelihood of a positive initial return increases with the mean initial return in recent IPOs (Spillover IR1) and it is higher for firms listing on Nasdaq. Moreover, the effect of the number of underwriters in the issue (Underwriter Count) varies with underwriter quality: it increases the probability that the issue is underpriced for top-tier underwriters and decreases this probability for lower-tier underwriters.

\section{Conclusions}

In this paper, we demonstrate that partial adjustment to public information is consistent with the information-based explanation for IPO underpricing proposed by Benveniste and Spindt (1989). Adding an informative public signal to their framework, we derive a rational Bayesian equilibrium, in which investors' private signals are conditionally correlated to the public signal.

In our model, public information is related to IPO underpricing through two channels. The first is a demand effect: the likelihood that there is sufficient demand for the issue to be underpriced is higher for a positive public signal. The second channel, which is new to the literature, is through investors' incentives to truthfully reveal their information. This incentive effect implies that investors require higher compensation (more underpricing) when the public signal is negative, tantamount to a higher conditional initial return.

We test these predictions for a sample of 6,300 IPOs in 1983-2012. As a proxy for private information, we use the residual from a regression of the offer price revision on the S\&P 500 return over the two months leading up to the issue. Consistent with the incentive effect, the relation between private information and the initial return is greater in falling markets than in rising markets. This effect is concentrated to issues sold by top-tier investment banks, where the order book is held to be most informative. Importantly, when we control for the incentive effect, the positive relation between the initial return and the market return disappears, hence resolving the puzzling predictability of initial returns.

We also find empirical support for the demand effect: the likelihood that the issue is underpriced increases in the public market return. While this result is not surprising, it helps complete our empirical examination of the model. 


\section{A Appendix}

The notation for our probabilistic assumptions and Bayes' rule is as follows:

$$
\begin{aligned}
V & =\{G=1, B=0\} \\
s_{i} & =\left\{g_{i}, b_{i}\right\} \\
s & =\{g, b\} \\
q\left(g_{i} \mid G\right)=q\left(b_{i} \mid B\right)=\gamma & >q\left(b_{i} \mid G\right)=q\left(g_{i} \mid B\right)=(1-\gamma) \\
q(g \mid G)=q(b \mid B)=\mu & >q(b \mid G)=q(g \mid B)=(1-\mu) \\
q(G)=\alpha & q(B)=(1-\alpha) \\
q(s)= & q(s \mid G) q(G)+q(s \mid B) q(B) .
\end{aligned}
$$

Assumptions (12) and (13) imply that the signals $\left(s_{i}, s\right)$ are informative. Hence,

$$
\begin{aligned}
q(G \mid g) & >q(G) \\
\frac{\mu \alpha}{\mu \alpha+(1-\mu)(1-\alpha)} & >\alpha \\
\mu & >\mu \alpha+(1-\mu)(1-\alpha) \\
(2 \mu-1) & >(2 \mu-1) \alpha \\
q(g \mid G)=\mu & >1 / 2 \\
q(G \mid g) & =\frac{q(g \mid G) q(G)}{q(g)} \\
q(B \mid g) & =(1-q(G \mid g)) \\
q(B \mid b) & =\frac{q(g \mid B) q(B)}{q(b)} \\
q(G \mid b) & =(1-q(B \mid b)),
\end{aligned}
$$

which holds for all $\alpha \in(0,1)$.

Moreover, the probability of $n$ positive private signals is given by

$$
\begin{aligned}
q(n \mid G) & \sim \operatorname{Binomial}[N, \gamma] \\
q(n \mid B) & \sim \operatorname{Binomial}[N,(1-\gamma)] \\
q(n \mid s) & =q(n \mid G) q(G \mid s)+q(n \mid B) q(B \mid s) .
\end{aligned}
$$

Finally the expected aftermarket value $v(n, s)$ is given by

$$
v(n, s)=G \times q(G \mid n, s)=1 \times \frac{q(n \mid G)}{q(n \mid s)} q(G \mid s) .
$$




\section{Proof of Lemma 1.}

It follows by Bayes' rule that

$$
q\left(g_{i} \mid g\right)=\frac{q\left(g_{i}, g\right)}{q(g)}
$$

where

$$
\begin{aligned}
q\left(g_{i}, g\right) & =q\left(g_{i}, g \mid G\right) q(G)+q\left(g_{i}, g \mid B\right) q(B) \\
& =q\left(g_{i} \mid G\right) q(g \mid G) q(G)+q\left(g_{i} \mid B\right) q(g \mid B) q(B) \\
& =\gamma \mu \alpha+(1-\gamma)(1-\mu)(1-\alpha) .
\end{aligned}
$$

Similarly,

$$
q(g)=q(g \mid G) q(G)+q(g \mid B) q(B)=\mu \alpha+(1-\mu)(1-\alpha)
$$

and hence

$$
q\left(g_{i} \mid g\right)=\frac{\gamma \mu \alpha+(1-\gamma)(1-\mu)(1-\alpha)}{\mu \alpha+(1-\mu)(1-\alpha)} .
$$

Since $\mu>1 / 2$ and $\gamma>1 / 2$, it is then immediate that

$$
q\left(g_{i} \mid b\right)=\frac{\gamma(1-\mu) \alpha+(1-\gamma) \mu(1-\alpha)}{(1-\mu) \alpha+\mu(1-\alpha)}
$$

and also that

$$
q\left(g_{i} \mid g\right)-q\left(g_{i} \mid b\right)=\frac{\alpha(1-\alpha)(2 \mu-1)(2 \gamma-1)}{[\mu \alpha+(1-\mu)(1-\alpha)][(1-\mu) \alpha+\mu(1-\alpha)]}>0 .
$$

It can similarly be shown that $q\left(b_{i} \mid b\right)>q\left(b_{i} \mid g\right)$ if $\mu>1 / 2$ and $\gamma>1 / 2$.

\section{Proof of Lemma 2.}

The allocation-weighted expectation of the other $N-1$ investors also receiving a positive signal $g_{i}$ is given by (note that $\bar{n} \geq 1$, hence $\hat{n} \in[0, N-1]$ )

$$
\sum_{\hat{n}=\bar{n}-1}^{N-1} \frac{1}{\hat{n}+1} \hat{q}\left(\hat{n} \mid g_{i}, s\right)=\sum_{\bar{n}-1}^{N-1} \frac{1}{\hat{n}+1} \hat{q}(\hat{n} \mid G) q\left(G \mid g_{i}, s\right)+\sum_{\bar{n}-1}^{N-1} \frac{1}{\hat{n}+1} \hat{q}(\hat{n} \mid G) q\left(B \mid g_{i}, s\right),
$$

where

$$
\begin{aligned}
\hat{q}(\hat{n} \mid G) & \sim \text { Binomial }[N-1, \gamma] \\
& =\left(\begin{array}{c}
N-1 \\
\hat{n}
\end{array}\right) \gamma^{\hat{n}}(1-\gamma)^{(N-1)-\hat{n}} \\
\hat{q}(\hat{n} \mid B) & \sim \text { Binomial }[N-1,(1-\gamma)] \\
& =\left(\begin{array}{c}
N-1 \\
\hat{n}
\end{array}\right)(1-\gamma)^{\hat{n}} \gamma^{(N-1)-\hat{n}} .
\end{aligned}
$$


Equation (20) can be reindexed using $\hat{n}=n-1$, which gives us

$$
\sum_{n=\bar{n}}^{N} \frac{1}{n} \hat{q}\left(n-1 \mid g_{i}, s\right)
$$

We need to show that the allocation-weighted expectation given one positive signal $g_{i}$ is equivalent to the unconditional expectation

$$
\sum_{n=\bar{n}}^{N} \frac{1}{n} \hat{q}\left(n-1 \mid g_{i}, s\right)=\frac{1}{N} \sum_{n=\bar{n}}^{N} q(n \mid s) .
$$

Given that $\left(\begin{array}{l}N-1 \\ n-1\end{array}\right) \frac{1}{n}=\frac{(N-1) !}{(n-1) ![(N-1)-(N-1)] !} \frac{1}{n}=\frac{N !}{n !(N-n) !} \frac{1}{N}=\left(\begin{array}{l}N \\ n\end{array}\right) \frac{1}{N}$ we have that

$$
\begin{aligned}
\frac{1}{n} \hat{q}(n-1 \mid G) q\left(G \mid g_{i}, s\right) & =\frac{1}{n}\left(\begin{array}{c}
N-1 \\
n-1
\end{array}\right) \gamma^{n-1}(1-\gamma)^{(N-1)-(n-1)} q\left(G \mid g_{i}\right) q(G \mid s) \\
& =\frac{1}{N}\left(\begin{array}{c}
N \\
n
\end{array}\right) \gamma^{n}(1-\gamma)^{N-n} q(G \mid s) \\
& =\frac{1}{N} q(n \mid G) q(G \mid s) .
\end{aligned}
$$

Hence, equation (22) must hold.

Conversely, given that $\left(\begin{array}{c}N-1 \\ n\end{array}\right) \frac{1}{N-n}=\frac{(N-1) !}{n !((N-1)-n] !} \frac{1}{N-n}=\frac{(N-1) !}{n ![N-(n+1)] !} \frac{1}{N-n}=\frac{N !}{n !(N-n) !} \frac{1}{N}$, we can similarly show that

$$
\sum_{n=0}^{\bar{n}-1} \frac{1}{N-n}\left(1-\frac{n}{\bar{n}}\right) \hat{q}\left(n \mid g_{i}, s\right)=\frac{\gamma}{N} \sum_{n=0}^{\bar{n}-1}\left(1-\frac{n}{\bar{n}}\right) q(n \mid s),
$$

which completes the proof.

\section{Proof of Proposition 1.}

The initial return associated with the high-demand state equals

$$
r(s)=\frac{v_{H}(s)}{p_{H}(s)}-1 ; s \in\{b, g\},
$$

where

$$
p_{H}(s)=v_{H}(s)-\frac{U_{L}(s)}{Q_{H}(s)} .
$$

We want to show that $r(g)<r(b)$, or that

$$
\frac{v_{H}(g)}{p_{H}(g)}<\frac{v_{H}(b)}{p_{H}(b)}
$$


Let $v_{H}(s)=\frac{\sum_{n=\bar{n}}^{N} q(n \mid s) v(n, s)}{\sum_{n=\bar{n}}^{N} q(n \mid s)}=\frac{\lambda_{H}(s)}{Q_{H}(s)}$ and hence $p_{H}(s)=\frac{\lambda_{H}(s)-U_{L}(s)}{Q_{H}(s)}$, and we get

$$
\begin{aligned}
\frac{\lambda_{H}(g)}{\lambda_{H}(g)-U_{L}(g)} & <\frac{\lambda_{H}(b)}{\lambda_{H}(b)-U_{L}(b)} \\
\frac{\lambda_{H}(b)-U_{L}(b)}{\lambda_{H}(b)} & <\frac{\lambda_{H}(g)-U_{L}(g)}{\lambda_{H}(g)} \\
1-\frac{U_{L}(b)}{\lambda_{H}(b)} & <1-\frac{U_{L}(g)}{\lambda_{H}(g)} \\
\frac{U_{L}(g)}{\lambda_{H}(g)} & <\frac{U_{L}(b)}{\lambda_{H}(b)} .
\end{aligned}
$$

Keeping in mind that $q(n \mid s) v(n, s)=q(n \mid G) q(G \mid s)$, we get that

$$
\begin{aligned}
\frac{U_{L}(g)}{q(G \mid g) \sum_{n=\bar{n}}^{N} q(n \mid G)} & <\frac{U_{L}(g)}{q(G \mid b) \sum_{n=\bar{n}}^{N} q(n \mid G)} \\
\frac{U_{L}(G \mid g)}{q(G)} & <\frac{U_{L}}{q(G \mid b)} \\
\frac{q\left(g_{i} \mid G\right)}{q(G \mid g)} \sum_{n=0}^{\bar{n}-1}\left(1-\frac{n}{\bar{n}}\right) q(n \mid g)[v(n+1, g)-v(n, g)] & <\frac{q\left(g_{i} \mid G\right)}{q(G \mid b)} \sum_{n=0}^{\bar{n}-1}\left(1-\frac{n}{\bar{n}}\right) q(n \mid b)[v(n+1, b)-v(n, b)] \\
\frac{1}{q(G \mid g)} \sum_{n=0}^{\bar{n}-1}\left(1-\frac{n}{\bar{n}}\right) q(n \mid g)[v(n+1, g)-v(n, g)] & <\frac{1}{q(G \mid b)} \sum_{n=0}^{\bar{n}-1}\left(1-\frac{n}{\bar{n}}\right) q(n \mid b)[v(n+1, b)-v(n, b)] \\
\sum_{n=0}^{\bar{n}-1}\left(1-\frac{n}{\bar{n}}\right)\left[q(n+1 \mid G) \frac{q(n \mid g)}{q(n+1 \mid g)}-q(n \mid G)\right] & <\sum_{n=0}^{\bar{n}-1}\left(1-\frac{n}{\bar{n}}\right)\left[q(n+1 \mid G) \frac{q(n \mid b)}{q(n+1 \mid b)}-q(n \mid G)\right] \\
\sum_{n=0}^{n}\left(1-\frac{n}{\bar{n}}\right)\left[q(n+1 \mid G) \frac{q(n \mid g)}{q(n+1 \mid g)}\right] & <\sum_{n=0}^{\bar{n}-1}\left(1-\frac{n}{\bar{n}}\right)\left[q(n+1 \mid G) \frac{q(n \mid b)}{q(n+1 \mid b)}\right] \\
\sum_{n=0}^{\bar{n}-1}\left(1-\frac{n}{\bar{n}}\right) q(n+1 \mid G)\left[\frac{q(n \mid g)}{q(n+1 \mid g)}-\frac{q(n \mid b)}{q(n+1 \mid b)}\right] & <0,
\end{aligned}
$$

which holds if, for all $n \in[0, N-1]$, we have that

$$
\frac{q(n+1 \mid g)}{q(n \mid g)}>\frac{q(n+1 \mid b)}{q(n \mid b)} .
$$

Let $\Gamma=\frac{1-\gamma}{\gamma}$ such that

$$
\begin{aligned}
\frac{q(n+1 \mid s)}{q(n \mid s)} & =\frac{\left(\begin{array}{c}
N \\
n+1
\end{array}\right)}{\left(\begin{array}{c}
N \\
n
\end{array}\right)} \frac{\gamma^{(n+1)}(1-\gamma)^{N-(n+1)} q(G \mid s)+\gamma^{N-(n+1)}(1-\gamma)^{(n+1)} q(B \mid s)}{\gamma^{n}(1-\gamma)^{N-n} q(G \mid s)+\gamma^{N-n}(1-\gamma)^{n} q(B \mid s)} \\
& =\frac{\left(\begin{array}{c}
N \\
n+1
\end{array}\right)}{\left(\begin{array}{c}
N \\
n
\end{array}\right)} \frac{\Gamma^{N-(n+1)} q(G \mid s)+\Gamma^{(n+1)} q(B \mid s)}{\Gamma^{N-n} q(G \mid s)+\Gamma^{n} q(B \mid s)} .
\end{aligned}
$$


Hence, equation (32) becomes

$$
\begin{gathered}
\frac{\Gamma^{N-(n+1)} q(G \mid g)+\Gamma^{(n+1)} q(B \mid g)}{\Gamma^{N-n} q(G \mid g)+\Gamma^{n} q(B \mid g)}>\frac{\Gamma^{N-(n+1)} q(G \mid b)+\Gamma^{(n+1)} q(B \mid b)}{\Gamma^{N-n} q(G \mid b)+\Gamma^{n} q(B \mid b)} \\
\frac{\Gamma^{N} q(G \mid g)+\Gamma^{2(n+1)} q(B \mid g)}{\Gamma^{N} q(G \mid g)+\Gamma^{2 n} q(B \mid g)}>\frac{\Gamma^{N} q(G \mid b)+\Gamma^{2(n+1)} q(B \mid b)}{\Gamma^{N} q(G \mid b)+\Gamma^{2 n} q(B \mid b)} .
\end{gathered}
$$

Using that

$$
\begin{gathered}
\frac{\Gamma^{N} q(G \mid s)+\Gamma^{2(n+1)} q(B \mid s)+\Gamma^{2 n} q(B \mid s)-\Gamma^{2 n} q(B \mid s)}{\Gamma^{N} q(G \mid s)+\Gamma^{2 n} q(B \mid s)}= \\
1+\frac{\Gamma^{2 n+2} q(B \mid s)-\Gamma^{2 n} q(B \mid s)}{\Gamma^{N} q(G \mid s)+\Gamma^{2 n} q(B \mid s)} \\
1-\frac{\left(1-\Gamma^{2}\right) \Gamma^{2 n} q(B \mid s)}{\Gamma^{N} q(G \mid s)+\Gamma^{2 n} q(B \mid s)},
\end{gathered}
$$

we get

$$
\begin{aligned}
-\Gamma^{2 n}\left(1-\Gamma^{2}\right) \frac{q(B \mid g)}{\Gamma^{N} q(G \mid g)+\Gamma^{2 n} q(B \mid g)} & >-\Gamma^{2 n}\left(1-\Gamma^{2}\right) \frac{q(B \mid b)}{\Gamma^{N} q(G \mid b)+\Gamma^{2 n} q(B \mid b)} \\
\frac{q(B \mid b)}{\Gamma^{N} q(G \mid b)+\Gamma^{2 n} q(B \mid b)} & >\frac{q(B \mid g)}{\Gamma^{N} q(G \mid g)+\Gamma^{2 n} q(B \mid g)} \\
q(B \mid b)\left[\Gamma^{N} q(G \mid g)+\Gamma^{2 n} q(B \mid g)\right] & >q(B \mid g)\left[\Gamma^{N} q(G \mid b)+\Gamma^{2 n} q(B \mid b)\right] \\
\Gamma^{N} q(G \mid g) q(B \mid b) & >\Gamma^{N} q(G \mid b) q(B \mid g) .
\end{aligned}
$$

Using that $q(G \mid b)=[1-q(G \mid g)]$ and $q(B \mid g)=[1-q(B \mid b)]$, we have

$$
\begin{aligned}
\Gamma^{N} q(G \mid g) q(B \mid b) & >\Gamma^{N}[1-q(G \mid g)][1-q(B \mid b)] \\
\Gamma^{N} q(G \mid g) q(B \mid b) & >\Gamma^{N}[1-q(G \mid g)-q(B \mid b)+q(G \mid g) q(B \mid b)] \\
\Gamma^{N}[q(G \mid g)+q(B \mid b)-1] & >0 .
\end{aligned}
$$

As long as $\Gamma^{N}>0$, we have that

$$
\begin{aligned}
q(G \mid g)+q(B \mid b) & >1 \\
\frac{q(g \mid G) q(G)}{q(g)}+\frac{q(b \mid B) q(B)}{q(b)} & >1 \\
q(g \mid G) q(G) q(b)+q(b \mid B) q(B) q(g) & >q(g) q(b) \\
q(g \mid G) q(G) q(b)+q(b \mid B) q(B) q(g) & >[q(g \mid G) q(G)+q(g \mid B) q(B)] q(b) \\
q(b \mid B) q(B) q(g) & >q(g \mid B) q(B) q(b) \\
q(b \mid B) q(g) & >q(g \mid B) q(b) \\
\mu[\mu \alpha+(1-\mu)(1-\alpha)] & >(1-\mu)[\mu(1-\alpha)+(1-\mu) \alpha] \\
\mu^{2} \alpha & >(1-\mu)^{2} \alpha \\
\mu & >1 / 2 .
\end{aligned}
$$

Thus, for any $\gamma, \mu>1 / 2, \alpha \in(0,1)$ and $\Gamma^{N}>0$, we have that $r(N, g)<r(N, b)$. 


\section{Proof of Proposition 2.}

By Bayes' rule it follows that

$$
q(n \mid s)=q(n \mid G) q(G \mid s)+q(n \mid B) q(B \mid s) .
$$

We need to show that

$$
\begin{aligned}
Q_{H}(g) & >Q_{H}(b) \\
\sum_{n=\bar{n}}^{N} q(n \mid g) & >\sum_{n=\bar{n}}^{N} q(n \mid b) \\
\sum_{n=\bar{n}}^{N} q(n \mid G) q(G \mid g)+q(n \mid B) q(B \mid g) & >\sum_{n=\bar{n}}^{N} q(n \mid G) q(G \mid b)+q(n \mid B) q(B \mid b) \\
\sum_{n=\bar{n}}^{N} q(n \mid G) q(G \mid g)+\sum_{n=\bar{n}}^{N} q(n \mid B)(1-q(G \mid g)) & >\sum_{n=\bar{n}}^{N} q(n \mid G)(1-q(B \mid b))+\sum_{n=\bar{n}}^{N} q(n \mid B) q(B \mid b) .
\end{aligned}
$$

Let $Q_{G}=\sum_{n=\bar{n}}^{N} q(n \mid G)$ and $Q_{B}=\sum_{n=\bar{n}}^{N} q(n \mid B)$, such that

$$
\begin{aligned}
Q_{G} q(G \mid g)+Q_{B}[1-q(G \mid g)] & >Q_{G}[1-q(B \mid b)]+Q_{B} q(B \mid b) \\
{\left[Q_{G}-Q_{B}\right] q(G \mid g) } & >\left[Q_{G}-Q_{B}\right]-\left[Q_{G}-Q_{B}\right] q(B \mid b) \\
{\left[Q_{G}-Q_{B}\right][q(G \mid g)+q(B \mid b)] } & >\left[Q_{G}-Q_{B}\right],
\end{aligned}
$$

which holds if $q(G \mid g)+q(B \mid b)>1$ and $Q_{G}>Q_{B}$. We showed that the first part holds if $\mu>1 / 2$ in proposition 1 . What remains is therefore to show that

$$
\begin{aligned}
\sum_{n=\bar{n}}^{N} q(n \mid G) & >\sum_{n=\bar{n}}^{N} q(n \mid B) \\
1-\sum_{n=0}^{\bar{n}-1} q(n \mid G) & >1-\sum_{n=0}^{\bar{n}-1} q(n \mid B) \\
\sum_{n=0}^{\bar{n}-1} q(n \mid B) & >\sum_{n=0}^{\bar{n}-1} q(n \mid G) .
\end{aligned}
$$

Equation (52) is the definition of the cumulative distribution function of $G$ first-order stochastically dominating $B$ for $n \in[0, N-1]$, which holds for any $\gamma>(1-\gamma)$. Also note that the equality in (52) is achieved only in (52) for $n=N$. Hence, (52) holds for any $\gamma>1 / 2$, which completes the proof. 


\section{Proof of Proposition 3.}

The proposition is proved by showing that

$$
\lim _{N \rightarrow \infty} \frac{\operatorname{Er}(g)}{\operatorname{Er}(b)}=\lim _{N \rightarrow \infty} \frac{r(g)}{r(b)} \frac{Q_{H}(g)}{Q_{H}(b)}>1 .
$$

Assuming that the signals are informative $(\gamma, \beta>1 / 2)$, taking the limit of (45) implies

$$
\lim _{N \rightarrow \infty} \frac{r(g)}{r(b)}=1
$$

From (51), it must be that

$$
\lim _{N \rightarrow \infty} \frac{Q_{H}(g)}{Q_{H}(b)}>1
$$

The only case where $Q_{H}(g)=Q_{H}(b)$ would be for $Q_{H}(g)=Q_{H}(g)=1$. This only happens if $\bar{n}=0$. Hence, (55) must hold, which completes the proof. 


\section{References}

Benveniste, Lawrence M., Alexander Ljungqvist, William J Wilhelm, and Xiaoyun Yu, 2003, Evidence of information spillovers in the production of investment banking services, Journal of Finance 58, 577-608.

Benveniste, Lawrence M., and Paul A. Spindt, 1989, How investment bankers determine the offer price and allocation of new issues, Journal of Financial Economics 24, 343-361.

Biais, Bruno, and Anne Marie Faugeron-Crouzet, 2002, Ipo auctions: English, Dutch,...French, and internet, Journal of Financial Intermediation 11, 9-36.

Bradley, Daniel J., and Bradford D. Jordan, 2002, Partial adjustment to public information and IPO underpricing, Journal of Financial and Quantitative Analysis 37, 595-616.

Busaba, Walid Y., Lawrence M. Benveniste, and Re-Jin Guo, 2001, The option to withdraw IPOs during the premarket: empirical analysis, Journal of Financial Economics 60, 73-102.

Busaba, Walid Y., and Chun Chang, 2010, Bookbuilding vs. fixed price revisited: The effect of aftermarket trading, Journal of Corporate Finance 16, 370-381.

Carter, Richard, and Steven Manaster, 1990, Initial public offerings and underwriter reputation, Journal of Finance 45, 1045-1067.

Chen, Zhaohui, and William J. Wilhelm, 2008, A theory of the transition to secondary market trading of IPOs, Journal of Financial Economics 90, 219-236.

Cornelli, Francesca, and David Goldreich, 2001, Bookbuilding and strategic allocation, The Journal of Finance 56, 2337-2370.

— 2003, Bookbuilding: How informative is the order book?, Journal of Finance 58, 14151444.

Derrien, François, 2005, IPO pricing in "hot" market conditions: Who leaves money on the table?, Journal of Finance 60, 487-521.

, and Kent L. Womack, 2003, Auctions vs. bookbuilding and the control of underpricing in hot IPO markets, Review of Financial Studies 16, 31-61.

Edelen, Roger M., and Gregory B. Kadlec, 2005, Issuer surplus and the partial adjustment of IPO prices to public information, Journal of Financial Economics 77, 347-373.

Hanley, Kathleen W., 1993, The underpricing of initial public offerings and the partial adjustment the underpricing of initial public offerings and the partial adjustment phenomenon, Journal of Financial Economics 34, 213-250.

Heckman, James J., 1979, Sample selection bias as a specification error, Econometrica 47, 153-161.

Ince, Özgür S., 2014, Why do IPO offer prices only partially adjust?, Quarterly Journal of Finance 4, 1450009 .

Jenkinson, Tim, and Howard Jones, 2004, Bids and allocations in European IPO bookbuilding, Journal of Finance 59, 2309-2338. 
Kutsuna, Kenji, Janet Kiholm Smith, and Richard L. Smith, 2009, Public information, IPO price formation, and long-run returns: Japanese evidence, Journal of Finance 64, 505-546.

Kyle, Albert S., 1985, Continuous auctions and insider trading, Econometrica 53, 1315-1335.

Leite, Tore, 2007, Adverse selection, public information, and underpricing in IPOs, Journal of Corporate Finance 13, 813-828.

Ljungqvist, Alexander, 2007, IPO underpricing, in B. E. Eckbo, ed.: Handbook of Corporate Finance: Empirical Corporate Financevol. 1 . chap. 7, pp. 375-422 (Elsevier/North-Holland, Handbooks in Finance Series).

Logue, Dennis E., 1973, On the pricing of unseasoned equity issues: 1965-1969, Journal of Financial and Quantitative Analysis 8, 91-103.

Loughran, Tim, and Jay R. Ritter, 2002, Why don't issuers get upset about leaving money on the table in IPOs?, Review of Financial Studies 15, 413-443.

Lowry, Michelle, Micah S. Officer, and G. William Schwert, 2010, The variability of IPO initial returns, Journal of Finance 65, 425-465.

Lowry, Michelle, and G. William Schwert, 2004, Is the IPO pricing process efficient?, Journal of Financial Economics 71, 3-26.

Sherman, Ann E., 2005, Global trends in IPO methods: Book building versus auctions with endogenous entry, Journal of Financial Economics 78, 615-649.

Wang, Wei, and Chris Yung, 2011, Ipo information aggregation and underwriter quality, Review of Finance 15, 301-325. 


\section{Table 1: Sample Initial IPO Return and Pre-issue Market Return}

The table shows the average initial return and pre-issue market return by year for the sample of 6,301 U.S. IPOs filed in the period 1983 to 2012 . The initial return is $I R 1=p_{1} / p_{0}-1$, where $p_{1}$ is the closing price on the first trading day and $p_{0}$ is the offer price, winsorized at $200 \%$. Public is the return on the S\&P500 index (S\&P500) over the 42 trading days leading up to the issue. $N$ is the number of observations.

\begin{tabular}{|c|c|c|c|c|c|c|c|c|c|}
\hline \multirow[b]{3}{*}{ Year } & \multirow{3}{*}{$\begin{array}{c}\text { All IPOs } \\
\mathrm{N} \\
(1) \\
\end{array}$} & \multicolumn{4}{|c|}{ Completed IPOs } & \multicolumn{4}{|c|}{ Withdrawn IPOs } \\
\hline & & \multirow[b]{2}{*}{$\begin{array}{l}\mathrm{N} \\
(2) \\
\end{array}$} & \multirow{2}{*}{$\begin{array}{c}\text { IR1 } \\
\text { Mean } \\
(3) \\
\end{array}$} & \multicolumn{2}{|c|}{ Public } & \multirow[b]{2}{*}{$\begin{array}{l}\mathrm{N} \\
(6) \\
\end{array}$} & \multirow{2}{*}{$\begin{array}{c}\% \text { of } \\
\text { sample } \\
(7)\end{array}$} & \multicolumn{2}{|c|}{ Public } \\
\hline & & & & $\begin{array}{c}\text { Mean } \\
(4) \\
\end{array}$ & $\begin{array}{c}\text { \% Positive } \\
(5)\end{array}$ & & & $\begin{array}{c}\text { Mean } \\
(8) \\
\end{array}$ & $\begin{array}{c}\% \text { Positive } \\
(9) \\
\end{array}$ \\
\hline 1983 & 244 & 243 & 10.4 & 1.6 & 60.5 & 1 & 0.4 & -3.2 & 0.0 \\
\hline 1984 & 111 & 105 & 6.9 & 0.8 & 57.1 & 6 & 5.4 & 0.7 & 50.0 \\
\hline 1985 & 110 & 102 & 5.7 & 4.0 & 82.4 & 8 & 7.3 & 5.4 & 87.5 \\
\hline 1986 & 276 & 236 & 14.3 & 2.8 & 72.5 & 40 & 14.5 & 1.1 & 60.0 \\
\hline 1987 & 187 & 165 & 12.9 & 6.1 & 86.1 & 22 & 11.8 & 2.8 & 90.9 \\
\hline 1988 & 64 & 59 & 5.3 & 1.1 & 61.0 & 5 & 7.8 & 0.1 & 40.0 \\
\hline 1989 & 80 & 66 & 7.7 & 3.2 & 69.7 & 14 & 17.5 & 3.6 & 78.6 \\
\hline 1990 & 100 & 77 & 10.2 & -0.2 & 55.8 & 23 & 23.0 & 2.2 & 73.9 \\
\hline 1991 & 240 & 224 & 11.9 & 1.5 & 60.7 & 16 & 6.7 & 2.2 & 50.0 \\
\hline 1992 & 354 & 304 & 10.5 & 2.0 & 65.8 & 50 & 14.1 & 0.9 & 66.0 \\
\hline 1993 & 441 & 393 & 12.8 & 1.3 & 76.3 & 48 & 10.9 & 1.0 & 77.1 \\
\hline 1994 & 369 & 317 & 8.9 & -0.5 & 44.2 & 52 & 14.1 & -0.1 & 50.0 \\
\hline 1995 & 391 & 344 & 21.4 & 4.9 & 100.0 & 47 & 12.0 & 4.8 & 97.9 \\
\hline 1996 & 585 & 536 & 16.9 & 3.9 & 85.6 & 49 & 8.4 & 4.4 & 83.7 \\
\hline 1997 & 420 & 351 & 15.1 & 5.1 & 86.0 & 69 & 16.4 & 5.8 & 84.1 \\
\hline 1998 & 292 & 214 & 25.5 & 4.9 & 79.9 & 78 & 26.7 & 1.3 & 52.6 \\
\hline 1999 & 439 & 377 & 66.9 & 2.6 & 72.4 & 62 & 14.1 & 2.9 & 72.6 \\
\hline 2000 & 392 & 311 & 52.9 & 0.1 & 49.5 & 81 & 20.7 & -1.8 & 40.7 \\
\hline 2001 & 135 & 58 & 16.3 & 0.2 & 48.3 & 77 & 57.0 & -7.2 & 15.6 \\
\hline 2002 & 63 & 49 & 10.9 & -3.7 & 24.5 & 14 & 22.2 & -4.5 & 21.4 \\
\hline 2003 & 55 & 47 & 12.3 & 3.4 & 100.0 & 8 & 14.5 & 3.5 & 87.5 \\
\hline 2004 & 143 & 129 & 12.5 & 2.3 & 68.2 & 14 & 9.8 & -0.5 & 21.4 \\
\hline 2005 & 154 & 134 & 12.1 & 1.5 & 67.9 & 20 & 13.0 & 1.7 & 80.0 \\
\hline 2006 & 148 & 124 & 13.6 & 2.6 & 80.6 & 24 & 16.2 & 2.1 & 70.8 \\
\hline 2007 & 156 & 132 & 14.9 & 1.6 & 67.4 & 24 & 15.4 & 1.2 & 54.2 \\
\hline 2008 & 41 & 17 & 6.4 & -3.2 & 29.4 & 24 & 58.5 & -3.2 & 33.3 \\
\hline 2009 & 43 & 35 & 11.3 & 5.0 & 97.1 & 8 & 18.6 & 6.5 & 75.0 \\
\hline 2010 & 90 & 78 & 9.4 & 3.4 & 71.8 & 12 & 13.3 & -1.2 & 41.7 \\
\hline 2011 & 84 & 69 & 14.8 & 1.7 & 65.2 & 15 & 17.9 & -0.4 & 33.3 \\
\hline 2012 & 94 & 73 & 16.0 & 3.9 & 86.3 & 21 & 22.3 & 0.9 & 61.9 \\
\hline Total & 6301 & 5369 & 19.7 & 2.5 & 72.0 & 932 & 14.8 & 0.9 & 60.1 \\
\hline
\end{tabular}




\section{Table 2: Initial Filing Range Statistics}

Panel A and B report the frequency and distribution, respectively, of the price revision (Revision), defined as the offer price relative to the midpoint of the pricing range in the initial SEC filing. Panel $\mathrm{C}$ shows the conditional average price revision in $\%$, while Panel D reports the conditional mean value of our estimate for private information, Private, defined as the residual $\epsilon$ from the regression Revision $=\alpha+\beta_{1} *$ Public $+\beta_{2} *$ Public $*$ Within $+\beta_{3} *$ Within $+\epsilon$, where Revision is the update in the offer price from the filing range midpoint and Within indicates an offer price within the filing range. The sample IPOs are allocated according to their price revision: Below range, Within range (Lowest endpoint (Min), Negative revision $(\mathrm{Min}<\mathrm{Neg}<0)$, Zero revision (0), Positive revision $(0<\operatorname{Pos}<$ Max), and Highest endpoint (Max)), and Above range. In each panel, the sample is further split by underwriter rank: Top-tier and Lower-tier indicate that the highest-ranked underwriter has a Carter and Manaster (1990) rank=9 and rank $<9$, respectively. The sample consists of 5,369 completed book-built U.S. IPOs filed in 1983-2012 and priced at the endpoint of, or outside of, the pricing range.

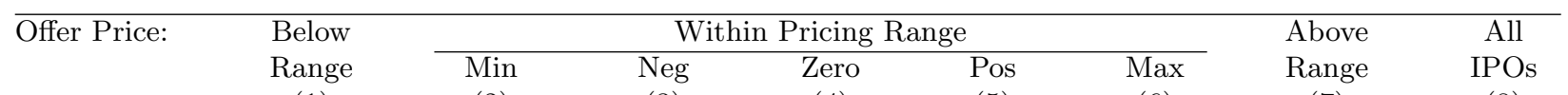

$\begin{array}{llllllll}(1) & (2) & (3) & (4) & (5) & (6) & (7) & \end{array}$

Panel A: Frequency distribution (N) of Revision

$\begin{array}{lcccccccc}\text { Top-tier } & 634 & 334 & 96 & 295 & 99 & 461 & 788 & 2707 \\ \text { Lower-tiers } & 713 & 430 & 210 & 318 & 167 & 391 & 433 & 2662 \\ \text { All } & 1347 & 764 & 306 & 613 & 266 & 852 & 1221 & 5369\end{array}$

Panel B: Distribution of Revision in \%

$\begin{array}{llllllllr}\text { Top-tier } & 23 \% & 12 \% & 4 \% & 11 \% & 4 \% & 17 \% & 29 \% & 50 \% \\ \text { Lower-tiers } & 27 \% & 16 \% & 8 \% & 12 \% & 6 \% & 15 \% & 16 \% & 50 \% \\ \text { All } & 25 \% & 14 \% & 6 \% & 11 \% & 5 \% & 16 \% & 23 \% & 100 \%\end{array}$

Panel C: Conditional average Revision

\begin{tabular}{lrrrrrrrr} 
Top-tier & $-21.9 \%$ & $-7.7 \%$ & $-3.9 \%$ & $0.0 \%$ & $3.8 \%$ & $7.2 \%$ & $21.4 \%$ & $1.4 \%$ \\
Lower-tiers & $-24.1 \%$ & $-9.2 \%$ & $-4.9 \%$ & $0.0 \%$ & $4.5 \%$ & $8.4 \%$ & $23.7 \%$ & $-3.0 \%$ \\
All & $-23.1 \%$ & $-8.5 \%$ & $-4.6 \%$ & $0.0 \%$ & $4.2 \%$ & $7.7 \%$ & $22.3 \%$ & $-0.8 \%$ \\
\multicolumn{2}{l}{ Panel D: Conditional average value of Private } & & & & \\
Top-tier & $-19.5 \%$ & $-7.4 \%$ & $-3.8 \%$ & $0.0 \%$ & $3.9 \%$ & $7.3 \%$ & $22.0 \%$ & $2.2 \%$ \\
Lower-tiers & $-21.8 \%$ & $-9.0 \%$ & $-4.7 \%$ & $0.0 \%$ & $4.5 \%$ & $8.3 \%$ & $24.3 \%$ & $-2.2 \%$ \\
All & $-20.7 \%$ & $-8.3 \%$ & $-4.5 \%$ & $0.0 \%$ & $4.3 \%$ & $7.8 \%$ & $22.9 \%$ & $0.0 \%$ \\
\hline
\end{tabular}




\section{Table 3: Variable Definitions}

The table shows the names and definitions of, and sources for, the variables used in the analysis. Ken French and Jay Ritter refer to their respective data webpages.

\begin{tabular}{llc}
\hline Name & Definition & Sources \\
\hline
\end{tabular}

\section{A: Variables critical for testing the model}

Revision

IR1

Public

Private

$P O S, N E G$

Top-tier

Lower-tier

\section{B: Control variables}

Age

Primary

Amount Filed

Spillover Revision

Spillover IR1

Spillover Withdrawn

Underwriter Count

High Tech

$\mathrm{VC}$

Nasdaq

Within
Price revision Revision $=p_{0} / p_{\text {mid }}-1$, where $p_{0}$ is the final offer price and $p_{\text {mid }}$ is the midpoint of the pricing range in the initial SEC filing.

Initial return $I R 1=p_{1} / p_{0}-1$, where $p_{1}$ is the firm's closing price on the first trading day and $p_{0}$ is the final offer price, winsorized at $200 \%$. Proxy for underpricing.

Return on the S\&P500 index over the 42 trading days preceding the issue. Proxy for public information during the book building period.

Proxy for private information. The residual from the regression Revision $=\alpha+\beta_{1} *$ Public $+\beta_{2} *$ Public $*$ Within $+\beta_{3} *$ Within $+\epsilon$, where $W$ ithin indicates an offer price within the filing range.

The subscripts $P O S$ and $N E G$ indicate a dummy taking the value of one if the variable is positive and non-positive, respectively.

Dummy indicating that at least one of the underwriters has a Carter and Manaster (1990) rank of 9.

Dummy indicating that all of the underwriters has a Carter and Manaster (1990) rank below 9.

Log of firm age since the founding year.

Percentage of shares sold in IPO as primary share (new issue).

Log of total $\$$ amount filed in the IPO.

Price revision spillover. The average Revision, orthogonalized to Public, for all IPOs in the 42 trading days prior to listing.

Initial return spillover. The average $I R 1$, orthogonalized to Spillover Revision and Public, for all IPOs in the 42 trading days prior to listing.

The number of withdrawn IPOs in the 42 trading days prior to listing.

Log of the number of underwriters in the IPO.

Indicator that the IPO firm is a high-technology firm.

Indicator that the IPO firm is backed by a venture capital firm.

Indicator that the IPO firm is listed on Nasdaq.

Indicator that the IPO was priced Within the Initial Filing Range.
SDC

SDC, CRSP

CRSP

SDC, CRSP

SDC

SDC

Jay Ritter

SDC

SDC

SDC, CRSP

SDC, CRSP

SDC

SDC

SDC

SDC

CRSP

CRSP

Ken French 


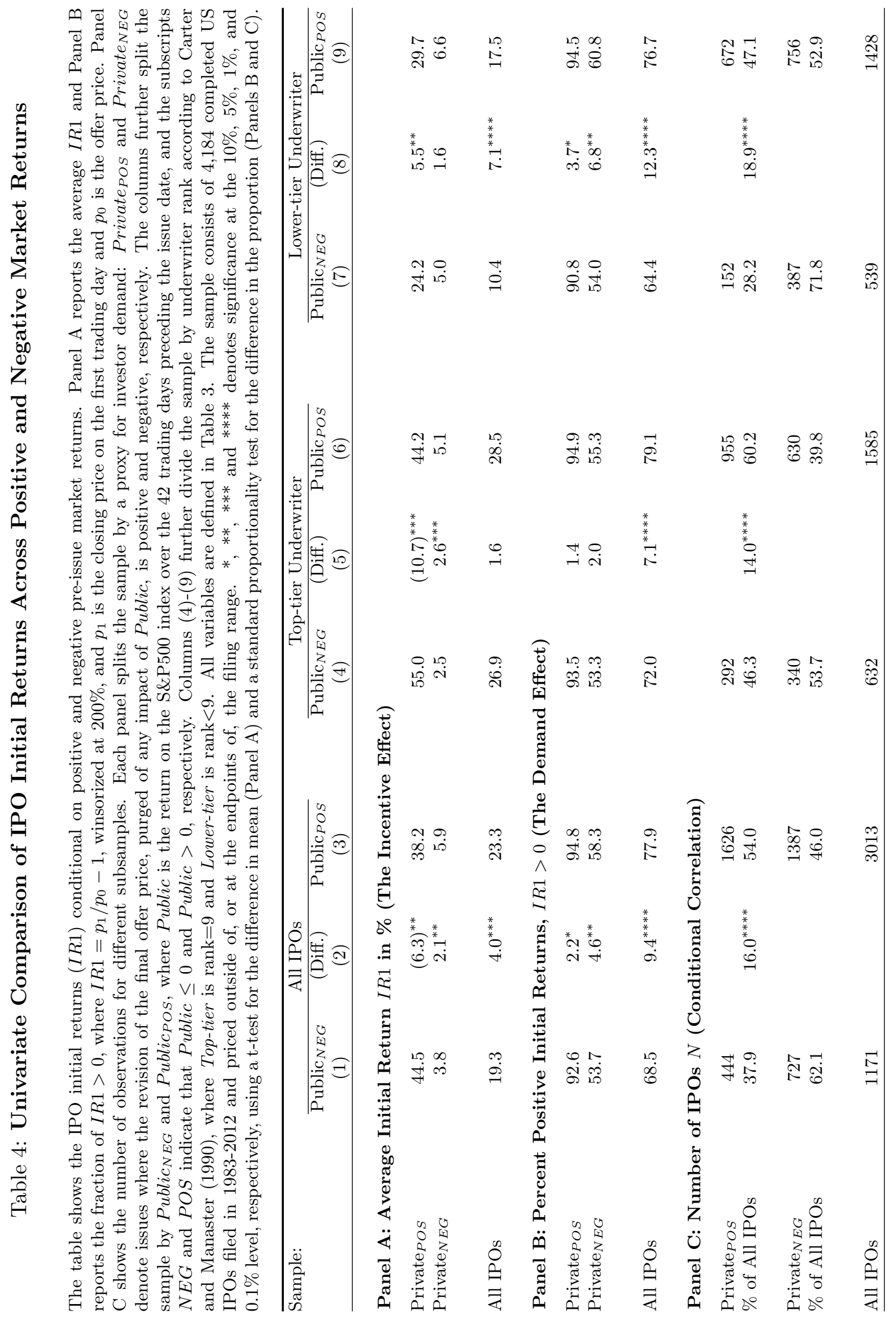




\section{Table 5: Probability of Completing the IPO}

The table reports the coefficient estimates from a probit regression for the probability that a filed IPO is completed vs. withdrawn prior to the issue. Column (1) uses the full sample, while columns (2) and (3) split the sample by underwriter rank: Top-tier and Lower-tier indicate that the highest-ranked underwriter has a Carter and Manaster (1990) $\mathrm{rank}=9$ and $\mathrm{rank}<9$, respectively. All variables are defined in Table 3. The z-scores (in parenthesis) use standard errors clustered by Fama-French 49 industry. *,**,*** and **** denote significance at the 10\%, 5\%, 1\%, and $0.1 \%$ level, respectively. The sample consists of 6,301 book-built U.S. IPOs filed in the period 1983 to 2012 .

\begin{tabular}{|c|c|c|c|}
\hline Sample: & $\begin{array}{l}\text { All IPOs } \\
\quad(1)\end{array}$ & $\begin{array}{l}\text { Top-tier Underwriter } \\
(2) \\
\end{array}$ & $\begin{array}{l}\text { Lower-tier Underwriter } \\
\qquad(3)\end{array}$ \\
\hline Public*$P u b l i c_{P O S}$ & $\begin{array}{l}-2.141^{* * *} \\
(-2.97)\end{array}$ & $\begin{array}{l}-0.320 \\
(-0.36)\end{array}$ & $\begin{array}{l}-3.466^{* * * *} \\
(-3.39)\end{array}$ \\
\hline Public $^{*}$ Public $_{N E G}$ & $\begin{array}{l}10.244^{* * * *} \\
(11.80)\end{array}$ & $\begin{array}{l}8.534^{* * * *} \\
(7.38)\end{array}$ & $\begin{array}{l}11.900^{* * * *} \\
(8.77)\end{array}$ \\
\hline Underwriter Count & $\begin{array}{l}1.007^{* * * *} \\
(16.20)\end{array}$ & $\begin{array}{l}1.244^{* * * *} \\
(12.89)\end{array}$ & $\begin{array}{l}0.680^{* * * *} \\
(10.11)\end{array}$ \\
\hline Amount Filed & $\begin{array}{l}-0.503^{* * * *} \\
(-15.20)\end{array}$ & $\begin{array}{l}-0.475^{* * * *} \\
(-10.23)\end{array}$ & $\begin{array}{l}-0.535^{* * * *} \\
(-9.22)\end{array}$ \\
\hline Underwriter Rank & $\begin{array}{l}0.067^{* * * *} \\
(4.83)\end{array}$ & & $\begin{array}{l}0.106^{* * * *} \\
(8.29)\end{array}$ \\
\hline Spillover IR1 & $\begin{array}{l}-1.721^{* * * *} \\
(-14.98)\end{array}$ & $\begin{array}{l}-1.679^{* * * *} \\
(-7.35)\end{array}$ & $\begin{array}{l}-1.824^{* * * *} \\
(-7.37)\end{array}$ \\
\hline Spillover PU & $\begin{array}{l}-0.279 \\
(-0.72)\end{array}$ & $\begin{array}{l}-0.344 \\
(-0.66)\end{array}$ & $\begin{array}{l}-0.148 \\
(-0.28)\end{array}$ \\
\hline Spillover WD & $\begin{array}{l}-0.054^{* * * *} \\
(-10.27)\end{array}$ & $\begin{array}{l}-0.057^{* * * *} \\
(-6.82)\end{array}$ & $\begin{array}{l}-0.051^{* * * *} \\
(-7.72)\end{array}$ \\
\hline Constant & $\begin{array}{l}8.913^{* * * *} \\
(15.40)\end{array}$ & $\begin{array}{l}8.641^{* * * *} \\
(10.31)\end{array}$ & $\begin{array}{l}9.428^{* * * *} \\
(10.05)\end{array}$ \\
\hline Observations & 6,301 & 3,071 & 3,230 \\
\hline $\begin{array}{l}\text { of which completed } \\
\text { of which withdrawn }\end{array}$ & $\begin{array}{c}5,369 \\
932\end{array}$ & $\begin{array}{c}2,707 \\
364\end{array}$ & $\begin{array}{l}2,662 \\
568\end{array}$ \\
\hline Pseudo $R^{2}$ & 0.225 & 0.288 & 0.191 \\
\hline
\end{tabular}


Table 6: Tests for Partial Adjustment to Public Information

The table reports the coefficient estimates from OLS regressions for the initial return (IR 1$)$. Public is the return on the S\&P500 index over the 42 trading days leading up to the issue. Private is the residual $\epsilon$ from the regression Revision $=\alpha+\beta_{1} *$ Public $+\beta_{2} *$ Public $*$ Within $+\beta_{3} *$ Within $+\epsilon$, where Revision is the update in the offer price from the filing range midpoint and Within indicates an offer price within the filing range. The Inverse Mill's ratio is from the probit regressions in Table 5. All variables are defined in Table 3. The t-statistics (in parenthesis) use standard errors clustered by Fama-French 49 industry. *, **, *** and **** denotes significance at the $10 \%, 5 \%, 1 \%$, and $0.1 \%$ level, respectively. The sample consist of 6,301 book-built U.S. IPOs between 1983-2012.

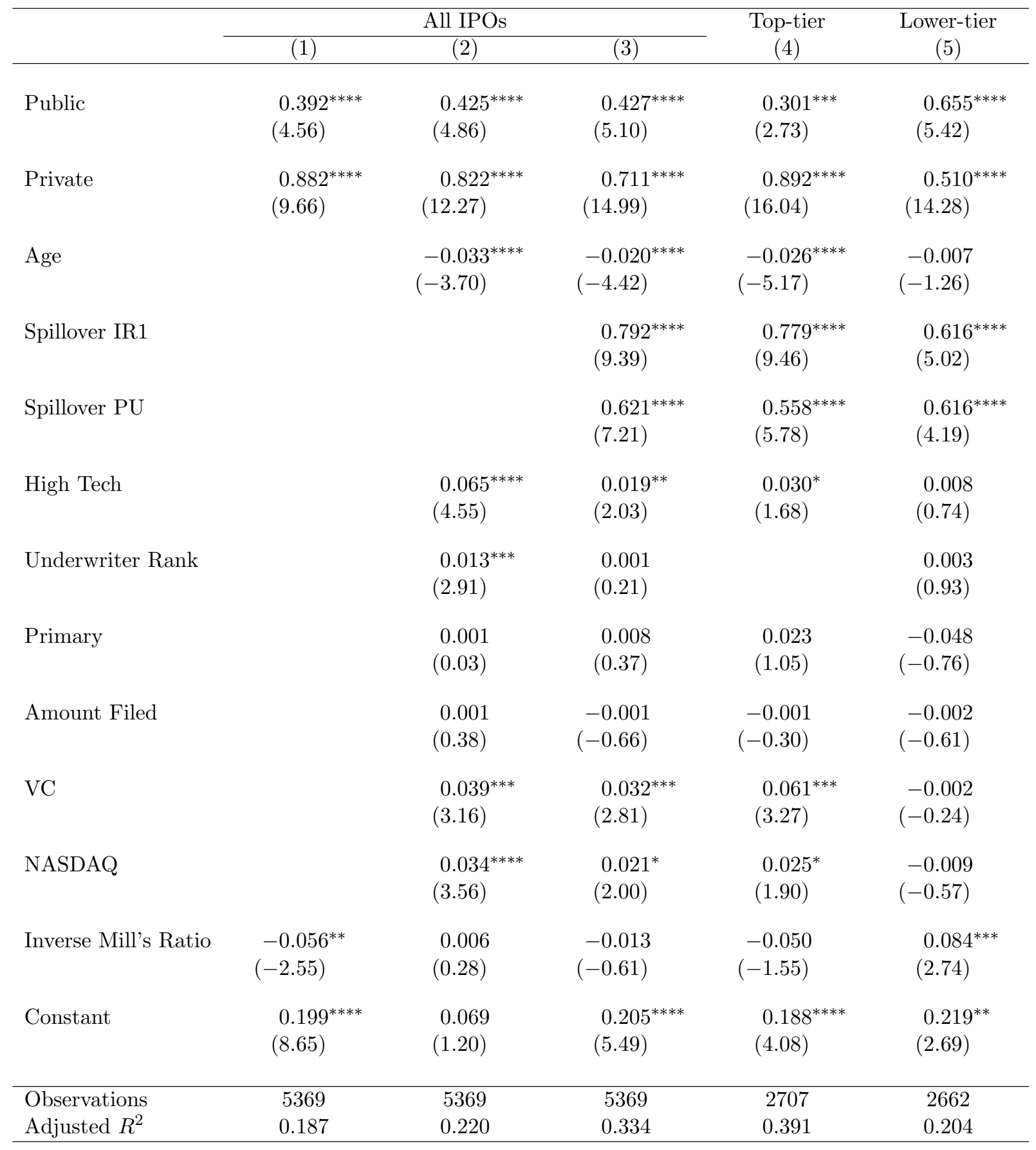


Table 7: Tests for the Incentive Effect

The table reports the coefficient estimates from OLS regressions for the initial return (IR1). Public is the return on the S\&P500 index over the 42 trading days leading up to the issue. Public $P O S$ is a dummy for Public $>0$. Private is the residual $\epsilon$ from the regression Revision $=\alpha+\beta_{1} *$ Public $+\beta_{2} *$ Public $*$ Within $+\beta_{3} *$ Within $+\epsilon$, where Revision is the update in the offer price from the filing range midpoint and Within indicates an offer price within the filing range. The Inverse Mill's ratio is from the probit regressions reported in Table 5. All variables are defined in Table 3. The t-statistics (in parenthesis) use standard errors clustered by Fama-French 49 industry. $*, * *, * * *$ and $* * * *$ denotes significance at the $10 \%, 5 \%, 1 \%$, and $0.1 \%$ level, respectively. The sample consist of 6,301 book-built U.S. IPOs between 1983-2012.

\begin{tabular}{|c|c|c|c|c|c|}
\hline & \multicolumn{3}{|c|}{ Full sample } & \multirow{2}{*}{$\begin{array}{c}\text { Top-tier } \\
(4)\end{array}$} & \multirow{2}{*}{$\begin{array}{c}\text { Lower-tier } \\
(5)\end{array}$} \\
\hline & $(1)$ & $(2)$ & $(3)$ & & \\
\hline Public & $\begin{array}{l}0.636^{* * * *} \\
(3.74)\end{array}$ & $\begin{array}{l}0.597^{* * * *} \\
(3.85)\end{array}$ & $\begin{array}{l}0.436^{* * *} \\
(3.11)\end{array}$ & $\begin{array}{r}0.267 \\
(1.43)\end{array}$ & $\begin{array}{l}0.686^{* * *} \\
(3.14)\end{array}$ \\
\hline Private & $\begin{array}{l}1.066^{* * * *} \\
(7.46)\end{array}$ & $\begin{array}{l}1.011^{\text {**** }} \\
(8.98)\end{array}$ & $\begin{array}{l}0.770^{* * * *} \\
(13.21)\end{array}$ & $\begin{array}{l}1.095^{* * * *} \\
(13.12)\end{array}$ & $\begin{array}{l}0.398^{* * * *} \\
(9.27)\end{array}$ \\
\hline Private $^{*}$ Public $_{P O S}$ & $\begin{array}{l}-0.240^{* * *} \\
(-3.22)\end{array}$ & $\begin{array}{l}-0.245^{* * * *} \\
(-3.53)\end{array}$ & $\begin{array}{l}-0.078^{* *} \\
(-2.57)\end{array}$ & $\begin{array}{l}-0.265^{* * * *} \\
(-4.16)\end{array}$ & $\begin{array}{l}0.145^{* * *} \\
(3.17)\end{array}$ \\
\hline Public $_{P O S}$ & $\begin{array}{l}-0.035^{* *} \\
(-2.19)\end{array}$ & $\begin{array}{l}-0.025^{*} \\
(-1.93)\end{array}$ & $\begin{array}{c}-0.002 \\
(-0.12)\end{array}$ & $\begin{array}{r}0.010 \\
(0.51)\end{array}$ & $\begin{array}{r}0.000 \\
(0.02)\end{array}$ \\
\hline Age & & $\begin{array}{l}-0.033^{* * * *} \\
(-3.69)\end{array}$ & $\begin{array}{l}-0.020^{* * * *} \\
(-4.39)\end{array}$ & $\begin{array}{l}-0.026^{* * * *} \\
(-5.08)\end{array}$ & $\begin{array}{l}-0.006 \\
(-1.20)\end{array}$ \\
\hline Spillover IR1 & & & $\begin{array}{l}0.788^{* * * *} \\
(9.40)\end{array}$ & $\begin{array}{l}0.770^{\text {**** }} \\
(9.47)\end{array}$ & $\begin{array}{l}0.624^{* * * *} \\
(4.96)\end{array}$ \\
\hline Spillover PU & & & $\begin{array}{l}0.617^{\text {**** }} \\
(7.24)\end{array}$ & $\begin{array}{l}0.539^{* * * *} \\
(5.65)\end{array}$ & $\begin{array}{l}0.623^{* * * *} \\
(4.18)\end{array}$ \\
\hline High Tech & & $\begin{array}{l}0.066^{* * * *} \\
(4.61)\end{array}$ & $\begin{array}{l}0.020^{* *} \\
(2.07)\end{array}$ & $\begin{array}{l}0.031^{*} \\
(1.71)\end{array}$ & $\begin{array}{r}0.007 \\
(0.64)\end{array}$ \\
\hline Underwriter Rank & & $\begin{array}{l}0.012^{* * *} \\
(2.95)\end{array}$ & $\begin{array}{c}0.001 \\
(0.19)\end{array}$ & & $\begin{array}{c}0.003 \\
(0.91)\end{array}$ \\
\hline Primary & & $\begin{array}{c}0.001 \\
(0.05)\end{array}$ & $\begin{array}{c}0.008 \\
(0.39)\end{array}$ & $\begin{array}{c}0.026 \\
(1.19)\end{array}$ & $\begin{array}{l}-0.047 \\
(-0.74)\end{array}$ \\
\hline Amount Filed & & $\begin{array}{r}0.001 \\
(0.38)\end{array}$ & $\begin{array}{l}-0.001 \\
(-0.67)\end{array}$ & $\begin{array}{l}-0.001 \\
(-0.29)\end{array}$ & $\begin{array}{l}-0.001 \\
(-0.51)\end{array}$ \\
\hline $\mathrm{VC}$ & & $\begin{array}{l}0.039^{* * *} \\
(3.21)\end{array}$ & $\begin{array}{l}0.033^{* * *} \\
(2.83)\end{array}$ & $\begin{array}{l}0.062^{* * *} \\
(3.34)\end{array}$ & $\begin{array}{l}-0.002 \\
(-0.23)\end{array}$ \\
\hline NASDAQ & & $\begin{array}{l}0.033^{* * *} \\
(3.52)\end{array}$ & $\begin{array}{l}0.021^{*} \\
(1.98)\end{array}$ & $\begin{array}{c}0.025^{*} \\
(1.95)\end{array}$ & $\begin{array}{l}-0.007 \\
(-0.47)\end{array}$ \\
\hline Inverse Mill's Ratio & $\begin{array}{l}-0.060^{* *} \\
(-2.60)\end{array}$ & $\begin{array}{r}0.002 \\
(0.08)\end{array}$ & $\begin{array}{c}-0.013 \\
(-0.64)\end{array}$ & $\begin{array}{c}-0.052 \\
(-1.59)\end{array}$ & $\begin{array}{l}0.083^{* * *} \\
(2.72)\end{array}$ \\
\hline Constant & $\begin{array}{l}0.220^{* * * *} \\
(8.27)\end{array}$ & $\begin{array}{r}0.088 \\
(1.51)\end{array}$ & $\begin{array}{l}0.206^{* * * *} \\
(4.90)\end{array}$ & $\begin{array}{l}0.178^{* * *} \\
(3.50)\end{array}$ & $\begin{array}{l}0.212^{* *} \\
(2.60)\end{array}$ \\
\hline Observations & 5369 & 5369 & 5369 & 2707 & 2662 \\
\hline Adjusted $R^{2}$ & 0.190 & 0.223 & 0.334 & 0.393 & 0.205 \\
\hline
\end{tabular}




\section{Table 8: Tests for the Demand Effect}

The table reports the coefficient estimates from probit regressions for the likelihood that the initial return is positive $\left(I R 1_{P O S}\right)$. Public is the return on the S\&P500 index over the 42 trading days leading up to the issue. Public $P O S$ is a dummy for Public $>0$. Private is the residual $\epsilon$ from the regression Revision $=\alpha+\beta_{1} *$ Public $+\beta_{2} *$ Public $*$ Within $+\beta_{3} *$ Within $+\epsilon$, where Revision is the update in the offer price from the filing range midpoint and Within indicates an offer price within the filing range. Columns (1)-(4) use the full sample, while columns (5) and (6) split the sample by underwriter rank: Top-tier and Lower-tier indicate that the highest-ranked underwriter has a Carter and Manaster (1990) rank=9 and rank $<9$, respectively. All variables are defined in Table 3 . The z-scores (in parenthesis) use standard errors clustered by Fama-French 49 industry. $* * *, * * *$ and $* * * *$ denotes significance at the $10 \%, 5 \%, 1 \%$, and $0.1 \%$ level, respectively. The sample consist of 5,369 completed book-built U.S. IPOs between 1983-2012.

\begin{tabular}{|c|c|c|c|c|c|c|}
\hline & \multicolumn{4}{|c|}{ All IPOs } & \multirow{2}{*}{$\begin{array}{c}\text { Top-tier } \\
(5)\end{array}$} & \multirow{2}{*}{$\begin{array}{l}\text { Lower-tier } \\
(6)\end{array}$} \\
\hline & (1) & $(2)$ & $(3)$ & $(4)$ & & \\
\hline Public & $\begin{array}{l}3.858^{\text {**** }} \\
(7.66)\end{array}$ & & $\begin{array}{l}3.887^{\text {**** }} \\
(7.90)\end{array}$ & & $\begin{array}{l}3.199^{* * * *} \\
(4.00)\end{array}$ & $\begin{array}{l}4.881^{\text {**** }} \\
(8.74)\end{array}$ \\
\hline Public $_{P O S}$ & & $\begin{array}{l}0.264^{* * * *} \\
(4.51)\end{array}$ & & $\begin{array}{l}0.275^{* * * *} \\
(4.85)\end{array}$ & & \\
\hline Private & $\begin{array}{l}3.181^{* * * *} \\
(23.04)\end{array}$ & $\begin{array}{c}3.134^{* * * *} \\
(23.15)\end{array}$ & $\begin{array}{l}3.216^{* * * *} \\
(24.02)\end{array}$ & $\begin{array}{l}3.177^{* * * *} \\
(23.84)\end{array}$ & $\begin{array}{l}3.724^{* * * *} \\
(19.13)\end{array}$ & $\begin{array}{l}2.766^{* * * *} \\
(13.01)\end{array}$ \\
\hline Age & & & $\begin{array}{c}0.001 \\
(0.07)\end{array}$ & $\begin{array}{r}-0.001 \\
(-0.05)\end{array}$ & $\begin{array}{c}-0.006 \\
(-0.20)\end{array}$ & $\begin{array}{r}0.011 \\
(0.38)\end{array}$ \\
\hline Underwriter Count & & & $\begin{array}{c}0.013 \\
(0.52)\end{array}$ & $\begin{array}{c}0.020 \\
(0.81)\end{array}$ & $\begin{array}{l}0.103^{* *} \\
(2.52)\end{array}$ & $\begin{array}{l}-0.092^{* *} \\
(-2.51)\end{array}$ \\
\hline Spillover IR1 & & & $\begin{array}{l}0.510^{* * *} \\
(2.78)\end{array}$ & $\begin{array}{l}0.521^{\text {*** }} \\
(3.07)\end{array}$ & $\begin{array}{c}0.230 \\
(1.04)\end{array}$ & $\begin{array}{l}0.836^{* *} \\
(2.39)\end{array}$ \\
\hline Spillover PU & & & $\begin{array}{c}-0.393 \\
(-1.63)\end{array}$ & $\begin{array}{l}-0.477^{* *} \\
(-2.06)\end{array}$ & $\begin{array}{l}-0.509^{*} \\
(-1.66)\end{array}$ & $\begin{array}{c}-0.092 \\
(-0.20)\end{array}$ \\
\hline High Tech & & & $\begin{array}{c}0.030 \\
(0.52)\end{array}$ & $\begin{array}{c}0.032 \\
(0.56)\end{array}$ & $\begin{array}{c}0.062 \\
(0.83)\end{array}$ & $\begin{array}{c}-0.004 \\
(-0.05)\end{array}$ \\
\hline Primary & & & $\begin{array}{c}-0.060 \\
(-0.51)\end{array}$ & $\begin{array}{c}-0.049 \\
(-0.42)\end{array}$ & $\begin{array}{l}-0.017 \\
(-0.13)\end{array}$ & $\begin{array}{c}-0.186 \\
(-0.89)\end{array}$ \\
\hline Amount Filed & & & $\begin{array}{l}-0.026^{* *} \\
(-2.02)\end{array}$ & $\begin{array}{l}-0.025^{* *} \\
(-2.00)\end{array}$ & $\begin{array}{c}-0.027^{*} \\
(-1.83)\end{array}$ & $\begin{array}{c}-0.002 \\
(-0.16)\end{array}$ \\
\hline $\mathrm{VC}$ & & & $\begin{array}{c}0.040 \\
(0.86)\end{array}$ & $\begin{array}{c}0.036 \\
(0.77)\end{array}$ & $\begin{array}{c}0.086 \\
(1.54)\end{array}$ & $\begin{array}{c}0.025 \\
(0.31)\end{array}$ \\
\hline NASDAQ & & & $\begin{array}{l}0.097^{* *} \\
(2.28)\end{array}$ & $\begin{array}{l}0.100^{* *} \\
(2.32)\end{array}$ & $\begin{array}{c}0.031 \\
(0.51)\end{array}$ & $\begin{array}{l}0.167^{* * *} \\
(2.75)\end{array}$ \\
\hline Constant & $\begin{array}{l}0.713^{* * * *} \\
(19.07)\end{array}$ & $\begin{array}{c}0.612^{\text {**** }} \\
(12.91)\end{array}$ & $\begin{array}{l}1.095^{* * * *} \\
(4.26)\end{array}$ & $\begin{array}{l}0.964^{* * * *} \\
(3.70)\end{array}$ & $\begin{array}{l}0.962^{* * *} \\
(2.77)\end{array}$ & $\begin{array}{l}0.827^{\text {*** }} \\
(2.63)\end{array}$ \\
\hline $\begin{array}{l}\text { Observations } \\
\text { Pseude } R^{2}\end{array}$ & 5369 & 5369 & 5369 & 5369 & 2707 & 2662 \\
\hline & & 0.118 & 0.131 & 0.125 & 0.167 & 0.104 \\
\hline
\end{tabular}

